\title{
How to model a child in school? \\ A dynamic macro-simulation study for Tanzania ${ }^{\dagger}$
}

\author{
Hannah Schürenberg-Frosch*
}

\begin{abstract}
Universal primary education is regarded as one of the key pillars of sustainable development. The positive influence of education on growth is supported by many empirical studies. However, the effects of education on labor supply, poverty reduction and welfare as well as subsistence agriculture are hardly traceable in an econometric setup, given the complex interactions and the long-term nature of education. An economy-wide dynamic simulation model provides a well-suited toolkit to analyze the effects of increased school provision in these aspects and provides insights into the intertemporal aspects of the schooling decision of children.

We develop a macro-economic model which explicitly includes education and human capital allocation and takes into account that the possibility of child labor increases the opportunity costs of human capital formation. In an application for Tanzania, we find that a large scale investment program in education might have a negative effect on both GDP growth and high skilled labor supply in the short-term but leads to higher GDP and welfare as well as significantly reduced child labor supply in the medium to long term.
\end{abstract}

JEL classification: $\mathrm{O} 15, \mathrm{O} 29, \mathrm{I} 28$

Keywords: Education, Computable General Equilibrium, Aid, Public investment, Labor force, Production structure, distribution

\footnotetext{
${ }^{\dagger}$ Preliminary version, comments are most welcome.

The author thanks Volker Clausen for helpful suggestions.

*University of Duisburg-Essen, Universitätsstr. $\quad 12, \quad$ D-45117 Essen, Tel.: $\quad+49 \quad 201 \quad 183 \quad 3010$, hannah.schuerenberg-frosch@uni-due.de
} 
"A sustainable End to World poverty as We knOW it, [..] REQUiRe[S] THAT CITIZENS ARE EMPOWERED TO MAKE POSITIVE CHOICES AND PROVIDE FOR THEMSELVES AND THEIR FAMILIES." United Nations Millennium Declaration

\section{Introduction}

Universal primary education ranges prominently among the Millennium Development Goals and is thus regarded as an important component of human development. In addition, education is widely believed to allow a country to access a higher steady state growth path by accumulating human capital. Consequently, education is one of the key pillars in the development strategies of all African countries and is also one of the main areas in which development aid is given on a large scale. Spending aid on education is also seen as a way to prevent Dutch Disease by reducing bottlenecks in scarce skill supply in the economy [See Heller, 2005].

Empirical cross-country evidence, such as Barro [1997] and Barro \& Sala-i-Martin [2003], confirms that human capital measured by years of schooling has a positive influence on growth due to increased productivity of workers. Even though this finding is considered as "weak" by authors such as Schultz [1999], Pritchett [2001] and Topel [1997], consensus prevails that very poor education hinders economic development. Schooling does not only have direct positive effects on human development like lower child mortality and better health status. It also provides the population with the skills required for democratic participation and a strong civil society.

Pritchett [2001] suggests that the seemingly low productivity payoff in terms of wage increases for higher skilled workers might partly be explained by low demand for these skills and thus emphasizes the importance of considering the demand side of the labor market as well. Schultz [1999] highlights the differences between primary and higher education in terms of social costs and distributional impact and concludes that Africa might have put too much weight on higher education. This is also in line with findings that primary education in general produces the highest social rate of return [See also Dreher et al., 2008]. An additional argument is that female primary education has a positive influence on child nutrition and children's health status and thus indirect positive effects on labor productivity. In addition, distributional aspects should be considered as reducing poverty is among the main objectives of aid policy. Gupta et al. [1999] and Gupta \& Verhoeven [2001] add that the efficiency of public investment and public spending is important for the success of large scale investment in education.

Against the background of the summarized empirical literature the efficiency of public 
investment planning, the structure of the labor force and the structure of production and thus demand for labor need to be integrated in the analysis. In addition, a distinction of primary, secondary and higher education is required, i.e. a distinction between different skill levels in the labor force. The distributional as well as structural consequences in reaction to investment in education should be regarded as well. Jung \& Thorbecke [2003], Agenor et al. [2008] and Maisonnave \& Décaluwé [2010] suggest that a Computable General Equilibrium (CGE) model could provide additional insights in these respects. While Cloutier et al. [2008] investigate the effects of a reduction in education expenditure in Vietnam, Jung \& Thorbecke [2003], Agenor et al. [2008] and Maisonnave \& Décaluwé [2010] investigate the effect of an increase in public capital for education in different African countries. While Agenor et al. [2008] assume that only educated labor is used in production, Jung \& Thorbecke [2003] in their model for Tanzania and Zambia and Maisonnave \& Décaluwé [2010] for South-Africa directly model the choice between different skill levels. Both papers develop a recursive dynamic model where the endogenous skill choice of the labor force does not only depend on the wage differential but also on the level of public capital in education. They find that increasing public capital in education has moderate growth effects. Jung \& Thorbecke [2003] find that the production structure of the economy, the initial labor force structure as well as unemployment in the benchmark and targeting of the new investments have strong impacts on the results.

This paper takes Jung \& Thorbecke [2003] as a point of departure and adds a number of aspects to the model. Most importantly, we model the process of human capital building (i.e. schooling) and the human capital accumulation explicitly instead of including only the outcome of the educational process (i.e. the skill choice). This requires disaggregating skilled labor classes into the number of (physical) workers and the amount of human capital they have accumulated. In addition, the inclusion of schooling also allows to account for the effects of increased human capital accumulation on child labor employment and family income from child labor. ${ }^{1}$ Given that child labor is an important production factor in Tanzania as in other African countries, this adds further insights.

We find that in general the aggregate growth effect of higher enrollment rates is positive but small. The magnitude of the growth effect from increased schooling strongly depends on the availability not only of schooling facilities but also of teachers. If enrollment is increased mainly by raising the pupil-teacher ratio we do not find a growth effect. In addition, we find that the availability of enough schools and teachers alone leads to a strong endogenous decrease in child labor even if the government fails to enforce enrollment. The expected future return to education is high enough that a majority of the households accept the foregone earnings from child labor and send their child to school,

\footnotetext{
${ }^{1}$ This aspect of educational policy is also mentioned by Maisonnave \& Décaluwé [2010].
} 
once the opportunity is there.

A substantial increase in enrollment is necessary if human capital accumulation is intended to grow faster than the population. Only a fraction of all enrolled children will really accumulate human capital due to non-passing and lower quality of teaching if the pupil-teacher ratio increases.

On the production side we see that in the first years after an increase in enrollment the availability of skilled labor outside the public sector stagnates due to the requirement of additional teachers. In addition, some export-oriented agricultural sectors are very sensitive to decreases in child labor supply and face strongly declining output if enrollment is increased. We find clear indications that capital and also land constrain the production effect from increased high-skilled labor supply.

The remainder of this paper is structured as follows: The next section gives an overview of the CGE literature in this specific field. Section 3 describes our model in detail, followed by a description of the data. In section 5 we present the scenarios we simulate. Results are summarized in section 6 which is followed by a conclusion.

\section{CGE models on educational policy in Africa}

Our study uses a recursive-dynamic economy-wide macro-economic model with a detailed educational sector to analyze increases in investment for education in a Sub-Saharan African country, namely Tanzania. There exist three other studies that use comparable models: Jung \& Thorbecke [2003], Agenor et al. [2008] and Maisonnave \& Décaluwé [2010]. We combine several features from these models and hence we briefly describe these models here with a focus on the educational component.

Jung \& Thorbecke [2003] model an educational investment program in the two countries Zambia and Tanzania and compare the results. Their model is a neoclassical multisector recursive-dynamic CGE model comparable to the dynamic IFPRI model. Given their focus on the comparison of two countries, the model uses an aggregated production and household structure (three sectors, four households). The educational sector, however, is modeled in detail. They distinguish between unskilled, semi-skilled and skilled labor. The skill choice equation is derived outside the model. The decision whether to choose a higher level of schooling depends on the wage differential between the current skill level and the next skill level and the availability of educational institutions. The skill choice is made from one period to the next and labor supply is updated correspondingly. Their baseline path is characterized by a proportional growth in all skill classes (equal to population growth) and unskilled unemployment. The policy scenario models an increase in the availability of schools by $15 \%$. They find a positive but low GDP effect for both 
countries, but wage effects as well as effects on household incomes differ substantially between the two countries. This is attributed to differences in capital endowments and in the structure of unemployment between the countries.

Agenor et al. [2008] use a substantially more aggregated approach. Their model is a one-sector-one-household model leaving distributional and reallocation issues aside. Educational reform is modeled in the nested production function. Public capital in education enters the composite public education input which is needed to transform raw labor into educated labor which is afterward combined with public capital in health to form the effective labor supply. Hence the model does not account for a skill choice by the households as it assumes that only educated labor is used in production and it does not distinguish between different skill levels. However the decomposition of labor into the educational component and raw labor is an innovative way to measure the effects of investment in education. They conclude that a one-time permanent increase in aid allows the government to increase spending on health, education and infrastructure which leads to higher GDP growth and lower poverty. A distinction between the different spending purposes of aid is made in the text and also in the model, but the simulated shock affects all forms of public capital.

Maisonnave \& Décaluwé [2010] model the impact of schooling in a recursive dynamic setup for South Africa. They follow up on Jung and Thorbecke's approach of a three-step schooling system but explicitly include the decision-making by pupils in the model. The decision whether a pupil will graduate, drop-out or repeat the skill-level again dependents on the availability and quality of schools as well as on wages. Their model is very specifically tailored to the South African labor market as it accounts for ethnic differences in school attendance and unemployment. They find positive but moderate effects from better schooling quality on production and wages. At the disaggregate level, however, some sectors face declining production in reaction to an increase in the quality of schooling due to higher wages for all labor classes.

\section{Model description}

We use a model which is conceptually loosely based on the IFPRI recursive dynamic model as described in Thurlow [2004 $]^{2}$ and also used in Jung \& Thorbecke [2003] but formulated here as a mixed complementarity problem (MCP) ${ }^{3}$ and implemented with GAMS/MPSGE. A complete model code listing is included in the appendix.

We start from Jung \& Thorbecke [2003], combine features of the models described above

\footnotetext{
${ }^{2}$ See Arndt et al. [2010] and Thurlow \& Wobst [2006] for applications based on this model.

${ }^{3}$ See Rutherford [1999] and Markusen [2004] for a detailed description of the modeling approach.
} 
and add a number of major and minor features:

Most importantly, we adopt a decomposition of skilled labor into raw labor and human capital and combine this with a perspective on four different skill levels that are characterized by their human capital intensity. All different labor classes have a distinct production sector combining raw labor and human capital. Moreover, the educational production, i.e. school attendance of children, is explicitly included in our model. Thus, we are able to include the decision problem between childrens' labor supply and school attendance but also the conflict between public service provision and teacher employment. Jung \& Thorbecke [2003] do not explicitly account for the financing of new schooling facilities, the increase in public capital in education is exogenous in their model. We directly model the increase in public capital as financed by aid i.e. an external transfer to the government. Moreover, an improvement in education does not only require an increase in the availability of schools, but also higher public recurrent expenditure as it raises the demand for teachers. We therefore introduce the requirement for teachers in the production function for education and assume this spending component to be part of the government's budget.

In addition, as we directly model the production of education we are also able to include education explicitly into households' demand function, thus the demand for education becomes endogenous in our model. The endogenous skill choice in Jung \& Thorbecke [2003] is made from one period to the next. This neglects the fact that the lag between the increase in education facilities and the rising educated labor supply takes several years. We therefore include a longer lag here by disaggregating skilled labor into raw labor and years of schooling and assuming that a higher skilled worker requires more years of schooling. Over and above, in African developing countries the skill choice is not only dependent on the difference between the unskilled labor wage and the skilled labor wage. It also involves foregone family income from child labor as Maisonnave \& Décaluwé [2010] point out. We have chosen a dataset which incorporates child labor. Thus we include the endogenous choice between sending the child to school and sending it to work (mainly in agriculture) in some of our scenarios.

The datasets used in Jung \& Thorbecke [2003] have been aggregated to a very high level of aggregation ( 3 sectors, 4 households) in order to be able to compare the two countries in the application. As the provision of additional education has large-scale impacts on the sectoral production structure as well as on distribution, we keep the disaggregated structure of our dataset, which means that our model includes 38 sectors and 13 production factors as well as 12 household types (disaggregated by region, education of household head and income). The production factors are mainly different labor types highly disaggregated with respect to their skills (child labor, unskilled adults, adults who have not finished primary school, not finished secondary school, secondary and higher educated), 
two types of capital, subsistence composite and land. ${ }^{4}$ The data is for Tanzania in $2001 .^{5}$

Some minor changes are made concerning the government sector, household consumption and production as well as elasticities and functional specifications. These are mainly required by the structure of the data. We additionally adopt a different model closure, in accordance with Thurlow [2004], holding world market prices and the external balance fixed and allowing investment to adjust to changes in savings.

\subsection{Within-period specification}

Our model is a recursive-dynamic neoclassical CGE model with an Armington production structure. Hence, the agents in the economy optimize their behavior in each period given current prices, endowments and their preferences. Their decisions affect the evolution of the physical capital and human capital stock which is updated between periods. In general, agents in this kind of model display myopic behavior, however, we introduce some aspects of quasi-forward looking behavior in the schooling choices.

\subsubsection{Production function}

We use a 5-stage nested production function with a very detailed labor structure as shown in figure 1.

Domestic production $(x d)$ in each sector $i$ is produced as a combination of intermediates, land, the subsistence composite ${ }^{6}$ and value added. Value added is decomposed into capital and labor, where labor is a composite of high-skilled and lower skilled labor. We assume a Leontief structure for the top level nest and between agricultural and non-agricultural capital. Capital and labor are weakly substitutable $(\sigma=0.5)$ which is also true for the substitution between highskilled (LNFS, LSEC) and lowskilled (LNFP, LNON) labor. Labor of neighboring skill classes (LNFS and LSEC, LNFP and LNON) is highly substitutable. Child labor is one form of unskilled labor and highly substitutable with unskilled adults (LNON). Each skilled labor type (LNFP, LNFS, LSEC) is a Leontief combination of raw labor (LNON) and human capital (HC).

\footnotetext{
${ }^{4}$ An overview of all abbreviations for households, factors and sectors used in the remainder of the paper is given in table 9 in the appendix.

${ }^{5}$ There exist few African datasets with the required disaggregation into skill classes and including child labor. The given dataset allows to compare our results with those from Jung \& Thorbecke [2003] as well as with the effects of schooling projects that have been realised during the simulated period in reality and the datasets are comparable as all are provided by IFPRI.

${ }^{6}$ This refers to the non-decomposable inputs of capital and different labor classes in subsistence farming
} 


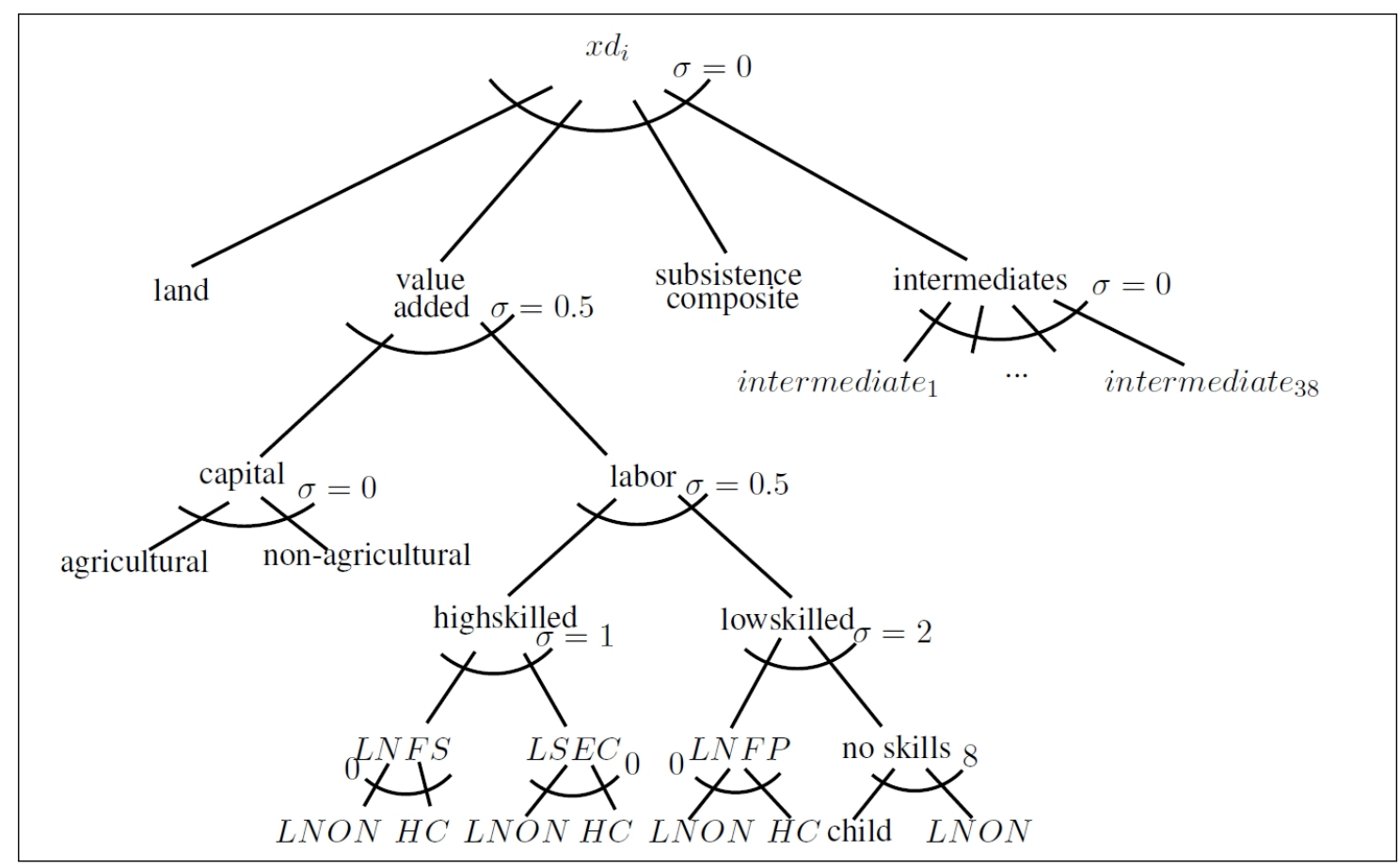

Figure 1: Nested production function

\subsubsection{Domestic supply}

Domestic production may either be used directly as home consumption $\left(h c_{i}\right)$ or be marketed $\left(x_{i}\right)$ either on the export $\left(e x_{i}\right)$ or on the domestic market $\left(d s_{i}\right)$. Domestic market sales are imperfect substitutes for imported goods $\left(i m_{i}\right)$ as the so called Armington specification implies. Depending on the sales market a trade and transport margin is added to the value of production and imports $\left(m x_{i}, m d_{i}, m i_{i}\right)$. (See figure 2.)

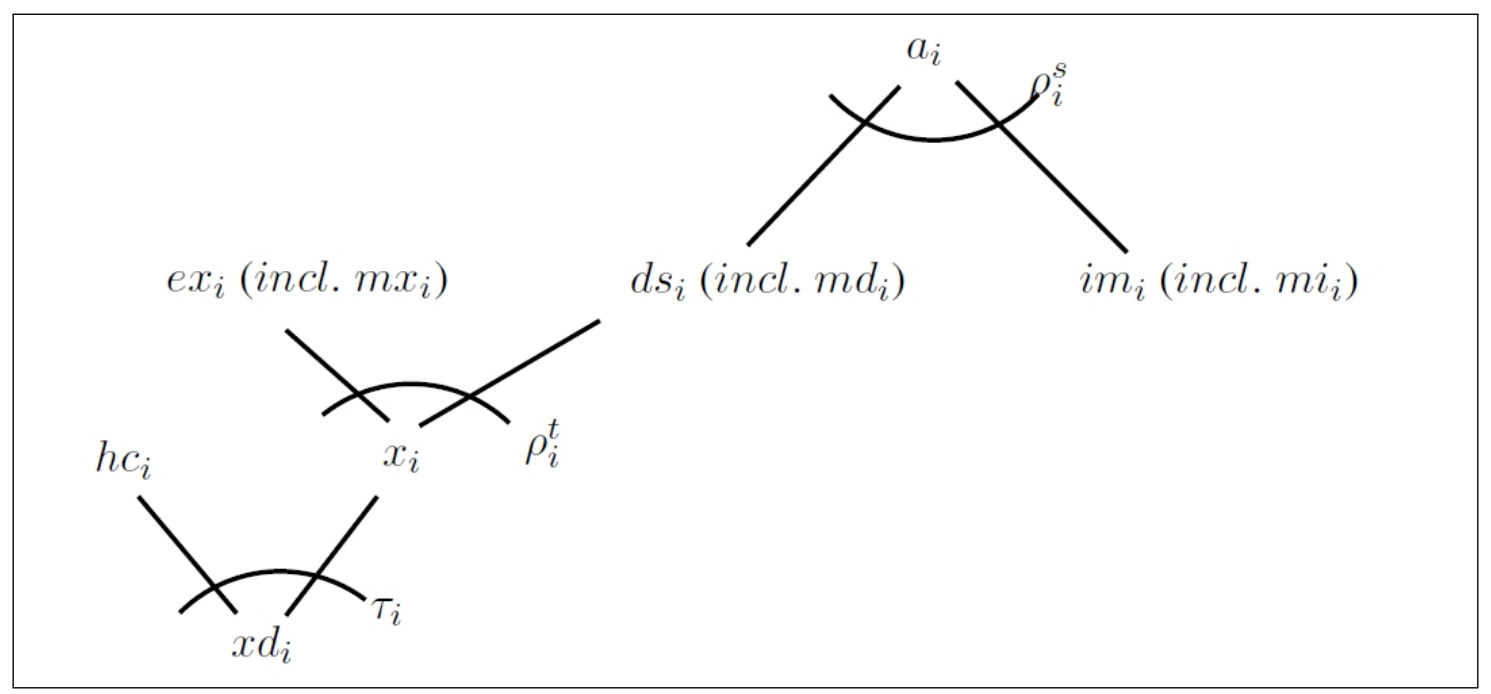

Figure 2: Sales markets 
The sectoral Armington elasticities $\left(\tau_{i}, \rho_{i}^{t}\right.$ and $\left.\rho_{i}^{s}\right)$ have been chosen in correspondence with other models in the literature and we explore their relevance in the sensitivity analysis. $^{7}$ The Armington elasticities are listed in table 11 in the appendix.

\subsubsection{Demand}

Households earn income from their endowment with labor, agricultural capital, physical enterprise capital, subsistence composite, land and human capital as well as from transfers and remittances. They use their income for consumption, direct tax payments, remittances, savings and education. Households endowment with human capital is in more detail described below.

Household preferences are modeled in a two-stage nested utility function. Consumption of goods is modeled in a Cobb-Douglas function. Demand for education depends positively on the income of the household, the current price of human capital, as a proxy for expected future return on human capital, and households initial demand for education, i.e. their endowment with children. The consumption nest and education are fairly imperfect substitutes $(s=0.5)$ in the households' utility top nest.

$$
U_{h}=U\left(\text { Cons, }_{\text {Ed }}^{+} \stackrel{+}{)}\right)
$$

The government earns income from indirect and direct taxes, import tariffs, foreign aid and public enterprises. It uses its income to provide public services, pay teachers, construct schools and for transfers to households and public savings.

Export demand for domestic products is perfectly elastic and adjusts to export supply. The rest of the world pays and receives remittances, transfers foreign aid and school capital to the government.

Investment demand is driven by savings.

\subsubsection{Human capital and education}

We decompose skilled and semi-skilled labor into the content of raw labor and human capital by matching our Social Accounting dataset with the underlying Labor Force Survey which shows how many workers correspond to the values of the Social Accounting Matrix (SAM). We suppose that the remaining value of skilled and semi-skilled labor except from the value of the (unskilled) raw worker is the value of the human capital the individual has accumulated. By matching the two datasets we find a non-linear relationship between

\footnotetext{
${ }^{7}$ See appendix for details.
} 
the years of schooling an individual has completed and the value of his human capital (see table 1$).^{8}$

\begin{tabular}{l|l|l|l|l}
\hline \hline Labor class & $\begin{array}{l}\text { Approx. } \\
\text { years of } \\
\text { schooling }\end{array}$ & $\begin{array}{l}\text { Estimated } \\
\text { share of } \\
\text { human } \\
\text { capital } \\
\text { in value } \\
\text { of worker } \\
(1-\theta)\end{array}$ & $\begin{array}{l}\text { Share of } \\
\text { total la- } \\
\text { bor force }\end{array}$ & $\begin{array}{l}\text { Share of } \\
\text { labor in- } \\
\text { come }\end{array}$ \\
& & $0 \%$ & $36.2 \%$ & $45.8 \%$ \\
Subsistence labor (FSUB) & $<2$ & $0 \%$ & $8.6 \%$ & $0.5 \%$ \\
Child labor (LCHILD) & 0 & $0 \%$ & $14.1 \%$ & $3.6 \%$ \\
No education (LNON) & $<2$ & $25 \%$ & $9.8 \%$ & $8.2 \%$ \\
Not finished primary school (LNFP) & $2-7$ & $30 \%$ & $29 \%$ & $28.4 \%$ \\
Not finished secondary school (LNFS) & $8-11$ & $95 \%$ & $2.4 \%$ & $13.6 \%$ \\
Secondary or higher education (LSEC) & $12+$ & \multicolumn{3}{l}{}
\end{tabular}

Table 1: Estimated labor force decomposition, own calculations based on Thurlow \& Wobst [2003].

Based on these coefficients we calculated the endowment with workers and human capital for each household type. Labor $(L)$ supply of every skill type $(s)$ except from "child", "subsistence" and "no education" are then modeled explicitly in a production function using the input coefficients shown in table 1 . Where human capital $(H C)$ and physical worker $\left(L_{n o n}\right)$ are of course complements meaning that each skill type has a Leontief production function combining the physical and the skill input. Skilled, semi-skilled and unskilled workers are then used in production as shown in figure 1.

$$
L_{s}=\theta L_{n o n}+(1-\theta) H C
$$

New human capital is produced by the education sector. Educational production $\left(S_{\text {edu }}\right)$ requires children, teachers and schools. Depending on the policy scenario we either define teachers and schools as complements or very imperfect substitutes. Educational production could be expanded by only increasing the number of pupils and schools without increasing the number of teachers which means bigger classes or expanding educational production by increasing the number of teachers (admin) and pupils without increasing the number of schools which could be realized by double shifting in class rooms, as is commonly done in African schools. In these cases teachers and schools are not strictly complements.

\footnotetext{
${ }^{8}$ We describe the decomposition and estimation procedure in the appendix.
} 


$$
S_{\text {edu }}=f\left(\text { children }, \stackrel{+}{+} d_{\text {admin }}^{+}, \text {schools }, p_{\text {admin }}^{-}, \stackrel{-}{w_{\text {child }}}, p_{\text {edu }}^{+}\right)
$$

Each child may either work or attend a school depending on the utility from education. We model this by introducing education into the households' demand function and making this demand dependent on the price of human capital (as a proxy for expected future return on human capital) and households' endowment with children. Thus, if the price for human capital is high, households will demand more education and thus, more children will attend school instead of working.

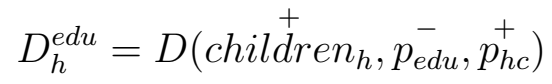

This will also have an increasing effect on childrens' wages $\left(w_{\text {child }}\right)$ as the number of child workers decreases. The indirect effect here is that the opportunity costs of sending a child to school grow. However, educational production will also expand if the availability of schools or teachers rises given the Leontief structure of the educational production function. In this case, however, the price of education will fall if there is excess production relative to demand by households. We also include scenarios where we enforce a $100 \%$ enrollment rate by exogenously setting labor demand for children to zero, which represents an effective ban on child labor. In this case the opportunity cost of sending a child to school is zero as the outside option of working is not given. Households' preferences will still be linked to the price of human capital. Hence, if the price of human capital is not growing households' utility from enforced schooling is low. The opportunity cost of sending a child to school is captured in the model by the wage for children. The utility from education is captured by the equilibrium price for education in household demand.

Given that teachers (i.e. public services in the dataset) are modeled as an input in education, a higher provision of education will lead to rising demand for semi-skilled and skilled workers. Hence, as long as the schooling process still takes place it creates a pressure on the market for skilled workers and leads to higher relative wages for high-skilled. Once the schooling from previous periods leads to growing supply of human capital, this bottleneck could be eliminated and the relative wage premium is reduced or disappears.

\subsubsection{Model closure}

The factor markets are closed by flexible wages that adjust to ensure that all exogenously fixed factor supply is used. We do not include unemployment as subsistence agriculture and home consumption is included as productive activity and thus official registered unemployment is partly included as subsistence labor in our data. 
External markets are cleared by flexible demand and supply on world markets and fixed world market prices as well as a fixed current account balance. All transfers within the country and between the country and the rest of the world are held constant. Investment adjusts to equal savings. Savings are determined by a fixed marginal propensity to save for each household. Hence, savings and investment demand grow with income.

\subsection{Between-period specification}

From one period to the next we update a number of variables, namely labor supply, physical and human capital stock and productivity.

\subsubsection{Labor force dynamics}

We assume that the supply of unskilled labor and the subsistence composite grows by $2.7 \%$ per year while the supply of children grows by $2.75 \%$ per year. Both numbers have been calculated based on the real development of the working age population and population aged 10-14 in the years 2001-2010.

The development of skilled labor supply of any skill class, however, is endogenous in our model (unlike in Jung \& Thorbecke [2003] who assume a proportional growth of all skill classes in their baseline) and depends on educational production in former years as well as demand for the different skill levels. Human capital accumulation is explained below. New labor is distributed to the household endowments proportionally to their initial endowment.

\subsubsection{Human capital accumulation}

The human capital stock grows if a child spends a year at school and does not have to repeat the class. It passes the final examination and either leaves the school, goes on to the next class or graduates. We have calculated the average pass rates from the educational transition matrix for Tanzania in Wobst \& Arndt [2004] and are thus able to calculate the number of successful pupils that have accumulated an additional unit of human capital. We discount this number by the pupil-teacher-ratio relative to the base year as we know from recent experiences in the two educational programs in Tanzania that a higher pupil-teacher ratio has led to lower pass-rates. ${ }^{9}$ New human capital is distributed to the households based on their endowment with children.

\footnotetext{
${ }^{9}$ See The World Bank [2005] and The World Bank [2011].
} 


\subsubsection{Capital stock dynamics}

The capital stocks in the base year have been calculated based on capital earnings and real interest and depreciation rates as found in Central Bank statistics and econometric studies. We update the capital stock by depreciating current capital by $6.5 \%$ and adding new investment as found in the model and adjusting this with an exogenous productivity parameter in order to match real rates of capital formation. The new capital stock is distributed to the households proportionally to their initial endowment with capital.

\subsubsection{School provision development}

In the baseline scenario we assume a moderate growth in the availability of both public capital in education and educational staff. The baseline growth rates of these two variables have been calculated from the development of the number of schools and the number of teachers in the 1990s. We could not use the real development in the simulation period as Tanzania realized two large scale education projects during this period. Hence we use the 1990s as a reference period. In our policy counterfactuals we raise either only the public investment in schools or both capital and recurrent public spending on education and investigate the differences in the results.

\subsubsection{Productivity growth}

As in most recursive dynamic CGE models we assume a baseline growth path for total factor productivity. In accordance with many CGE and econometric models as well as with Jung \& Thorbecke [2003] we chose total factor productivity in the baseline scenario in a way that leads to an approximate replication of the past GDP growth rates. This baseline productivity growth, which results at $5 \%$ in our model, as well as the adjustment of the capital stock is common for all scenarios and hence does not affect any conclusion about the different educational policies we simulate.

\section{Data}

We use the IFPRI SAM for Tanzania for 2001 as described in Thurlow \& Wobst [2003]. We chose Tanzania for several reasons: First, Tanzania and Zambia are natural candidates for our study as this allows to at least partly compare our results with those from Jung \& Thorbecke [2003]. Among these two, Tanzania was chosen because Tanzania has realized two large scale educational projects since the base year of the most recent SAM, hence we can compare our results with the experiences in reality. Moreover, the IFPRI Tanzania SAM is very rich in terms of educational disaggregation of the labor force and it provides information on child labor, both because it is linked to the very detailed Labor Force Survey 2000/2001. This degree of disaggregation was necessary in order to match 
our modeling of human capital production and accumulation. The availability of a Labor Force Survey for the same year provided important additional information and allowed to disaggregate skilled and semi-skilled labor into the two components raw labor and human capital appropriately. In addition, Tanzanian school statistics are also quite complete and provide a time series dimension. This information was helpful to find appropriate proxies for public capital in education, the baseline growth rate of schools and teachers and the total number of pupils between ages 10 and 14 .

We aggregate the data slightly in the sectoral dimension. Instead of the original 43 sectors, we retain 38 sectors. We keep the full detail of household and factor disaggregation, we only drop the gender-disaggregation in labor classes for reasons of simplicity and due to a lack of information on the gender of child labor. Table 8 in the appendix gives an overview of the household and labor class definitions.

Additional data on the labor force, population (population growth, young population, working age population, regional distribution of children and adults) and the schooling system (number of teachers, number of schools, enrollment by age group, enrollment by region) has been taken from the 2000/2001 Tanzania Labor Force Survey, the 2000/2001 Census and several editions of the National Basic Education Statistics (BSE). In addition, we have used Central Bank statistics to calculate the interest rate.

From schooling statistics we estimate the number of pupils that are between 10 and 14 years old (i.e. would be counted as child labor by the definition of our dataset if they worked instead of attending school) and the enrollment rates in these age groups for rural and urban regions. We could thus approximate the additional endowment with non-working children for the different households and define these as pupils.

Descriptive tables on the sectoral factor and trade intensities, households' income and spending structure are included in the appendix.

\section{Baseline assumptions and counterfactuals}

In the model briefly described above we simulate different scenarios which all represent educational policy programs. These are briefly summarized in table 2. 
Table 2: Scenario specification

\begin{tabular}{|c|c|c|c|c|c|}
\hline \multirow[t]{2}{*}{ Variable } & \multicolumn{5}{|c|}{ Scenario } \\
\hline & 0 & 1 & 2 & 3 & 4 \\
\hline School provision & $\begin{array}{l}\text { grows with popu- } \\
\text { lation growth rate } \\
(n)\end{array}$ & $\begin{array}{l}\text { grows by } 33 \% \text { in } \\
2002 \text { and after- } \\
\text { wards with rate } n\end{array}$ & $\begin{array}{l}\text { grows with popu- } \\
\text { lation growth rate } \\
(n)\end{array}$ & $\begin{array}{l}\text { grows with } n+2 \text { in } \\
2002 \& 2003, n+1 \\
\text { in } 2004, n+5 \text { in } \\
2005 \text { and } 2006 \text { and } \\
n \text { from } 2007 \text { on- } \\
\text { wards }\end{array}$ & $\begin{array}{l}\text { grows by } 33 \% \text { in } \\
2002 \text { and after- } \\
\text { wards with rate } n\end{array}$ \\
\hline Number of teachers & $\begin{array}{l}\text { grows with popu- } \\
\text { lation growth rate } \\
(n)\end{array}$ & endogenous & endogenous & endogenous & endogenous \\
\hline Pupil-teacher ratio & endogenous & constant & endogenous & endogenous & endogenous \\
\hline Child labor & Possible & Prohibited & Prohibited & Possible & Possible \\
\hline
\end{tabular}

In the first and second counterfactual we simulate a policy where the government enforces a $100 \%$ enrollment rate, i.e., we do not allow children to be employed. However, only in the first counterfactual we provide the required schooling resources to hold the pupil-school ratio and the pupil-teacher-ratio constant. This means a massive increase in the availability of schools (by 33.5\%) and in the employment of teaching staff in the first simulation period. Afterwards schooling investment and educational staff grow with the same growth rate as in the baseline scenario.

In the second counterfactual we also prohibit child labor but the government continues to increase schools and teachers only with the baseline growth rate. This means that the pupil-teacher and pupil-school ratio increase and probably some children will not find a place in a school.

In the third scenario we simulate a rather modest investment scenario with a continuous increase in public investment over the years which is based on the two projects that were realized in Tanzania during the simulation period. We simulate the following path for the number of schools: In 2002 and 2003 the number of schools increases by $2 \%$ plus the baseline growth. In 2004, an additional 1\% is added and in 2005 and $20065 \%$ on top of the baseline growth rate. Up from 2007, schools grow with the baseline growth rate. We assume the number of teachers to grow in accordance with the demand for teachers from the educational sector. However, we allow childrens' work as an outside option. In addition, we assume that the productivity of skilled labor grows by $10 \%$ up from 2005 due to increased quality in education.

In the forth counterfactual we assume that the government increases public investment by $33.5 \%$ like in the first scenario which means that now each child would have a place in school. However, we assume teaching staff employment to grow endogenously. We allow for a higher pupil-teacher ratio and hold the pupil-school ratio constant. Child labor is allowed as an outside option. 
It is assumed across all scenarios that the public investment (building of schools) is financed by aid whereas the additional teachers have to be financed from the governmental budget. Hence, educational policy is detrimental to other public service provision. We hold the population and productivity growth rates constant across the different counterfactuals.

\section{Results}

Table 3 shows the development of the educational inputs and production in the different scenarios. The public capital in schooling is always set exogenously whereas the number of teachers is only set exogenously in scenario 1 (implicitly by holding the pupil-teacher ratio constant). The number of pupils and educational production are determined in the model following households' demand for education and the working possibility for children. The human capital stock results from educational production and the pupil-teacher ratio in previous periods.

Table 3: Educational variables

\begin{tabular}{|c|c|c|c|c|c|c|c|c|c|c|c|}
\hline Variable & Scenario & 2001 & 2002 & 2003 & 2004 & 2005 & 2006 & 2007 & 2008 & 2009 & 2010 \\
\hline \multirow{5}{*}{$\begin{array}{l}\text { Public } \\
\text { capital in } \\
\text { schooling }\end{array}$} & $\mathbf{0}$ & 1.0000 & 1.0270 & 1.0547 & 1.0832 & 1.1125 & 1.1425 & 1.1733 & 1.2050 & 1.2376 & 1.2710 \\
\hline & 1 & 1.0000 & 1.5222 & 1.5641 & 1.6071 & 1.6513 & 1.6967 & 1.7434 & 1.7913 & 1.8406 & 1.8912 \\
\hline & 2 & 1.0000 & 1.0270 & 1.0547 & 1.0832 & 1.1125 & 1.1425 & 1.1733 & 1.2050 & 1.2376 & 1.2710 \\
\hline & 3 & 1.0000 & 1.0481 & 1.0984 & 1.1399 & 1.2298 & 1.3268 & 1.3633 & 1.4008 & 1.4393 & 1.4789 \\
\hline & 4 & 1.0000 & 1.5222 & 1.5641 & 1.6071 & 1.6513 & 1.6967 & 1.7434 & 1.7913 & 1.8406 & 1.8912 \\
\hline \multirow{5}{*}{$\begin{array}{l}\text { Number } \\
\text { of pupils }\end{array}$} & $\mathbf{0}$ & 1.0000 & 1.0402 & 1.0981 & 1.1592 & 1.2224 & 1.2880 & 1.3562 & 1.4274 & 1.5017 & 1.5796 \\
\hline & 1 & 1.0000 & 1.3185 & 1.5137 & 1.5702 & 1.6239 & 1.6797 & 1.7376 & 1.7977 & 1.8604 & 1.9259 \\
\hline & 2 & 1.0000 & 1.5747 & 1.6747 & 1.7809 & 1.8940 & 2.0142 & 2.1420 & 2.2779 & 2.4225 & 2.5762 \\
\hline & 3 & 1.0000 & 1.0374 & 1.0926 & 1.1446 & 1.2659 & 1.3712 & 1.4449 & 1.5057 & 1.5682 & 1.6330 \\
\hline & 4 & 1.0000 & 1.3544 & 1.4943 & 1.5687 & 1.6467 & 1.7280 & 1.8122 & 1.8996 & 1.9904 & 2.0850 \\
\hline \multirow{5}{*}{$\begin{array}{l}\text { Number } \\
\text { of } \\
\text { teachers }\end{array}$} & 0 & 1.0000 & 1.0160 & 1.0486 & 1.0848 & 1.1228 & 1.1627 & 1.2044 & 1.2480 & 1.2937 & 1.3413 \\
\hline & 1 & 1.0000 & 1.3185 & 1.5137 & 1.5702 & 1.6239 & 1.6797 & 1.7376 & 1.7977 & 1.8604 & 1.9259 \\
\hline & 2 & 1.0000 & 1.0270 & 1.0547 & 1.0832 & 1.1125 & 1.1425 & 1.1733 & 1.2050 & 1.2376 & 1.2710 \\
\hline & 3 & 1.0000 & 1.0374 & 1.0926 & 1.1446 & 1.2148 & 1.3061 & 1.3651 & 1.4108 & 1.4578 & 1.5066 \\
\hline & 4 & 1.0000 & 1.3702 & 1.5005 & 1.5413 & 1.5830 & 1.6276 & 1.6744 & 1.7235 & 1.7748 & 1.8285 \\
\hline \multirow{5}{*}{$\begin{array}{l}\text { Educational } \\
\text { production }\end{array}$} & 0 & 1.0000 & 1.0270 & 1.0548 & 1.0834 & 1.1128 & 1.1430 & 1.1740 & 1.2058 & 1.2385 & 1.2721 \\
\hline & 1 & 1.0000 & 1.5189 & 1.5635 & 1.6066 & 1.6510 & 1.6965 & 1.7433 & 1.7914 & 1.8408 & 1.8916 \\
\hline & 2 & 1.0000 & 1.0277 & 1.0555 & 1.0840 & 1.1133 & 1.1434 & 1.1742 & 1.2060 & 1.2385 & 1.2720 \\
\hline & 3 & 1.0000 & 1.0479 & 1.0983 & 1.1400 & 1.2298 & 1.3268 & 1.3635 & 1.4011 & 1.4397 & 1.4794 \\
\hline & 4 & 1.0000 & 1.5191 & 1.5632 & 1.6063 & 1.6506 & 1.6962 & 1.7429 & 1.7910 & 1.8404 & 1.8912 \\
\hline \multirow{5}{*}{$\begin{array}{l}\text { Pupil- } \\
\text { teacher } \\
\text { ratio }\end{array}$} & 0 & 1.0000 & 1.0000 & 1.0239 & 1.0472 & 1.0686 & 1.0887 & 1.1078 & 1.1261 & 1.1437 & 1.1608 \\
\hline & 1 & 1.0000 & 1.0000 & 1.0000 & 1.0000 & 1.0000 & 1.0000 & 1.0000 & 1.0000 & 1.0000 & 1.0000 \\
\hline & 2 & 1.0000 & 1.0000 & 1.5333 & 1.5878 & 1.6441 & 1.7025 & 1.7630 & 1.8255 & 1.8904 & 1.9575 \\
\hline & 3 & 1.0000 & 1.0000 & 1.0000 & 1.0000 & 1.0000 & 1.0421 & 1.0498 & 1.0584 & 1.0672 & 1.0757 \\
\hline & 4 & 1.0000 & 1.0000 & 0.9885 & 0.9959 & 1.0178 & 1.0403 & 1.0617 & 1.0823 & 1.1022 & 1.1215 \\
\hline \multirow{5}{*}{$\begin{array}{l}\text { Human } \\
\text { capital } \\
\text { stock }\end{array}$} & 0 & 1.0000 & 1.0211 & 1.0426 & 1.0648 & 1.0877 & 1.1114 & 1.1360 & 1.1615 & 1.1878 & 1.2152 \\
\hline & 1 & 1.0000 & 1.0211 & 1.0490 & 1.0810 & 1.1142 & 1.1485 & 1.1840 & 1.2207 & 1.2587 & 1.2980 \\
\hline & 2 & 1.0000 & 1.0211 & 1.0428 & 1.0651 & 1.0880 & 1.1115 & 1.1357 & 1.1605 & 1.1859 & 1.2121 \\
\hline & 3 & 1.0000 & 1.0211 & 1.0431 & 1.0661 & 1.0923 & 1.1201 & 1.1499 & 1.1811 & 1.2133 & 1.2466 \\
\hline & 4 & 1.0000 & 1.0211 & 1.0501 & 1.0818 & 1.1144 & 1.1478 & 1.1822 & 1.2176 & 1.2540 & 1.2916 \\
\hline
\end{tabular}

It is important to mention that the assumed size of public investment differs quite substantially across the scenarios: It is visible in the first section of table 3 that scenario 3 
which is based on the projects realized in Tanzania has a much lower investment compared to the high investment in scenarios 1 and 4 . However, the projects have not done most of the investment in the first year but the investment is splitted in two projects and grows gradually.

When children are not allowed to work by assumption (scenarios 1 and 2), the number of pupils at the end of the simulation period is about $89 \%$ higher then in 2001 and about $60 \%$ higher compared to simply continuing with current enrollment (scenario 0). Even if public investment is high enough to provide additional places in schools for every child currently working, if the pupil-teacher ratio is held constant, the endogenous employment of teachers is not sufficient to allow every child to go to school in scenario 1 . In scenario 2 all children are enrolled but at current school and teacher provision this would lead to about $50 \%$ more pupils per teacher.

Without additional investment and additional teachers (2), 100\% enrollment does not increase educational production significantly compared to the baseline-levels. On the other hand, if there is a sufficient school provision with enough teachers being employed, even if the outside option of working is retained (4) the majority of children is endogenously sent to school and educational production as well as human capital accumulation is nearly as high as with enforced mandatory schooling.

The effect on the stock of human capital, however, is modest even in the high investment scenarios 1 and 4 . This is mainly due to the fact that pass rates are on average at only $75 \%$ and that human capital accumulation is assumed to be slower if the pupil teacher ratio rises. In this aspect the reality-based scenario 3 lies in between the business as usual scenario 0 and the high investment provision in scenario 2.

In general, we see a slight welfare and GDP increase compared to the baserun in any of the scenarios with higher investment. However, the welfare effect as well as the production effect are rather small compared to the massive investment we simulate. It is highest in those scenarios where we have a large increase in school provision whereas it is smaller if school availability lacks behind the number of pupils. The welfare effect is highest in scenario 4 with high schooling provision and endogenous selection into school attendance.

In the case where child labor is prohibited but schooling is not sufficiently provided (2), we see a strong increase in the pupil-teacher ratio but nearly no effect on welfare and GDP compared to the baseline. This is because educational production and human capital accumulation do nearly not increase compared to the baseline as pupils do not find a sufficient schooling environment to learn and accumulate human capital while they do not have the alternative to work and thus do not produce something and earn income 
Table 4: Results: Macroeconomic aggregates (benchmark $=1$ )

\begin{tabular}{|c|c|c|c|c|c|c|c|c|c|c|c|}
\hline Variable & Scenario & 2001 & 2002 & 2003 & 2004 & 2005 & 2006 & 2007 & 2008 & 2009 & 2010 \\
\hline \multirow{5}{*}{ GDP } & 0 & 1.0000 & 1.0419 & 1.0862 & 1.1332 & 1.1833 & 1.2366 & 1.2934 & 1.3539 & 1.4185 & 1.4873 \\
\hline & 1 & 1.0000 & 1.0385 & 1.0839 & 1.1328 & 1.1847 & 1.2400 & 1.2987 & 1.3611 & 1.4275 & 1.4981 \\
\hline & 2 & 1.0000 & 1.0385 & 1.0826 & 1.1293 & 1.1790 & 1.2319 & 1.2882 & 1.3482 & 1.4121 & 1.4803 \\
\hline & 3 & 1.0000 & 1.0419 & 1.0863 & 1.1336 & 1.1836 & 1.2370 & 1.2944 & 1.3556 & 1.4208 & 1.4902 \\
\hline & 4 & 1.0000 & 1.0399 & 1.0853 & 1.1344 & 1.1865 & 1.2418 & 1.3005 & 1.3630 & 1.4294 & 1.5000 \\
\hline \multirow{5}{*}{ Welfare } & 0 & 1.0000 & 1.0413 & 1.0839 & 1.1280 & 1.1744 & 1.2232 & 1.2747 & 1.3290 & 1.3862 & 1.4466 \\
\hline & 1 & 1.0000 & 1.0417 & 1.0840 & 1.1294 & 1.1782 & 1.2296 & 1.2839 & 1.3413 & 1.4019 & 1.4659 \\
\hline & 2 & 1.0000 & 1.0393 & 1.0817 & 1.1253 & 1.1712 & 1.2195 & 1.2702 & 1.3235 & 1.3795 & 1.4385 \\
\hline & 3 & 1.0000 & 1.0418 & 1.0847 & 1.1287 & 1.1794 & 1.2305 & 1.2817 & 1.3365 & 1.3945 & 1.4558 \\
\hline & 4 & 1.0000 & 1.0479 & 1.0891 & 1.1348 & 1.1836 & 1.2347 & 1.2887 & 1.3457 & 1.4058 & 1.4694 \\
\hline \multirow{5}{*}{$\begin{array}{l}\text { GDP } \\
\text { growth } \\
\text { rate (in\%) }\end{array}$} & 0 & & 4.1909 & 4.2484 & 4.3291 & 4.4184 & 4.5067 & 4.5941 & 4.6807 & 4.7664 & 4.8516 \\
\hline & 1 & & 3.8514 & 4.3734 & 4.5048 & 4.5894 & 4.6626 & 4.7350 & 4.8064 & 4.8771 & 4.9473 \\
\hline & 2 & & 3.8514 & 4.2415 & 4.3157 & 4.4027 & 4.4877 & 4.5724 & 4.6566 & 4.7404 & 4.8241 \\
\hline & 3 & & 4.1927 & 4.2596 & 4.3521 & 4.4079 & 4.5198 & 4.6331 & 4.7274 & 4.8105 & 4.8902 \\
\hline & 4 & & 3.9913 & 4.3665 & 4.5216 & 4.5934 & 4.6605 & 4.7309 & 4.8009 & 4.8707 & 4.9403 \\
\hline \multirow{5}{*}{$\begin{array}{l}\text { GDP/ } \\
\text { Capita }\end{array}$} & $\mathbf{0}$ & 1.0000 & 1.0149 & 1.0314 & 1.0499 & 1.0708 & 1.0940 & 1.1200 & 1.1488 & 1.1808 & 1.2162 \\
\hline & 1 & 1.0000 & 1.0115 & 1.0292 & 1.0495 & 1.0722 & 1.0974 & 1.1253 & 1.1560 & 1.1898 & 1.2270 \\
\hline & 2 & 1.0000 & 1.0115 & 1.0278 & 1.0460 & 1.0665 & 1.0893 & 1.1148 & 1.1431 & 1.1745 & 1.2091 \\
\hline & 3 & 1.0000 & 1.0149 & 1.0316 & 1.0503 & 1.0710 & 1.0945 & 1.1209 & 1.1504 & 1.1831 & 1.2191 \\
\hline & 4 & 1.0000 & 1.0129 & 1.0306 & 1.0511 & 1.0740 & 1.0992 & 1.1271 & 1.1579 & 1.1917 & 1.2289 \\
\hline
\end{tabular}

for their households.

Annual GDP growth rates show a much more heterogeneous picture than GDP and reveal that the two scenarios with very high schooling investment (1 and 4) produce lower growth rates in the first period, followed by a growth boost when the additional human capital enters the labor market and remaining at higher growth rates afterwards, whereas the project scenario (3) leads to a slow but steady increase in GDP growth in 2002 to 2009.

GDP per capita, however, is declining in all scenarios and the educational investment alone is not capable to reverse this trend even though it reduces the decline. ${ }^{10}$

A more disaggregated perspective on factor supply (table 6) shows that, if skill choice is modeled endogenously most of the human capital accumulated will be used for semiskilled and high-skilled labor provision, the provision of labor with only primary skills even decreases.

Factor prices (table 5) reveal that, in reaction to the relative growth of labor in comparison to capital and land in combination with the assumed increase in capital productivity, rents on capital increase relative to the wages of unskilled labor but not to the level of high skilled wages. Most importantly, land rents increase relative to returns to all other factors. This shows that land acts as a rationing factor for an overall production response given its fixed supply and non-substitutability with other production factors. This sup-

\footnotetext{
${ }^{10}$ Please note, the reduction in GDP/Capita is due to the fact that we slightly underestimate the GDP growth in the baseline, which is a common phenomenon in developing country CGE. Comparisons among the scenarios nonetheless are valid as they are based on common assumptions.
} 
ports the arguments by other authors such as Schultz [1999] and Pritchett [2001] that schooling investment does not provide high social returns because labor is not equipped with enough resources to be highly productive. In our case land evolves as the rationing factor, however for other countries or with lower capital productivity capital might as well limit the productivity of additional skilled workers.

Table 5: Results: Factor prices in 2010, base year level $=1$

\begin{tabular}{l|rrrrrrrrr}
\hline \hline Scenario & FSUB & LCHILD & LNON & LNFP & LNFS & LSEC & CAPAG & CAPNAG & LAND \\
\hline $\mathbf{0}$ & 0.875 & 0.500 & 0.470 & 0.943 & 1.199 & 1.236 & 0.819 & 0.944 & 1.666 \\
$\mathbf{1}$ & 0.848 & 0.000 & 0.436 & 0.824 & 1.034 & 1.065 & 0.730 & 0.981 & 2.277 \\
$\mathbf{2}$ & 0.884 & 0.051 & 0.487 & 0.980 & 1.248 & 1.286 & 0.861 & 0.934 & 1.468 \\
$\mathbf{3}$ & 0.867 & 0.485 & 0.452 & 0.892 & 1.130 & 1.164 & 0.778 & 0.958 & 1.925 \\
$\mathbf{4}$ & 0.850 & 0.521 & 0.447 & 0.816 & 1.016 & 1.044 & 0.716 & 0.984 & 2.302 \\
\hline \hline
\end{tabular}

Child wages reflect the alternative costs of schooling. If children are not allowed to work (scenarios 1 and 2), the opportunity cost of sending the children to school is very low or even zero (in scenario 1). If schooling provision and demand for education rises, but the outside option of working is in place as well, the opportunity cost of going to school is positive and childrens' wages remain at a comparable level to unskilled adults' wages.

Table 6 summarizes the employment effects of the different policies. Unskilled labor employment grows faster than skilled employment due to lagged and costly provision of high skilled labor. Interestingly, primary skilled labor employment shows a non-monotonic development in most scenarios: during the first years a slight increase and later on a decrease. The main reason for this phenomenon is that secondary schooling requires primary schooling and thus in the first years additional primary skilled workers enter the labor market.

While an above-average proportion of the new semi skilled labor works outside the public sector, the opposite is true for high skilled labor. High skilled workers outside the public sector grow slower than the overall employment of these workers. Hence, indeed we find a diverting effect from other sectors to the public sector due to increased demand for teachers.

A further important and very positive result is that, even if child labor is not prohibited effectively, a sufficient school provision (scenario 4) reduces childrens' (endogenous) employment by $50 \%$ compared to the baseline case in 2010. However, even in the high investment scenarios 1 and 4, the ratio of skilled to unskilled labor decreases over time as human capital accumulation is slower than population growth.

At the sectoral level we find that not all sectors benefit from the general higher provision of labor. This mainly concerns export oriented agricultural sectors (coffee, cotton, cashew 
Table 6: Results: Employment (benchmark $=1$ )

\begin{tabular}{|c|c|c|c|c|c|c|c|c|c|c|c|}
\hline Factor category & Scenario & 2001 & 2002 & 2003 & 2004 & 2005 & 2006 & 2007 & 2008 & 2009 & 2010 \\
\hline \multirow{4}{*}{$\begin{array}{l}\text { Subsistence } \\
\text { composite }\end{array}$} & $\mathbf{0}$ & 1.000 & 1.063 & 1.130 & 1.201 & 1.277 & 1.357 & 1.442 & 1.533 & 1.630 & 1.732 \\
\hline & 1 & 1.000 & 1.063 & 1.130 & 1.201 & 1.277 & 1.357 & 1.442 & 1.533 & 1.630 & 1.732 \\
\hline & 2 & 1.000 & 1.063 & 1.130 & 1.201 & 1.277 & 1.357 & 1.442 & 1.533 & 1.630 & 1.732 \\
\hline & 4 & 1.000 & 1.063 & 1.130 & 1.201 & 1.277 & 1.357 & 1.442 & 1.533 & 1.630 & 1.732 \\
\hline \multirow{4}{*}{$\begin{array}{l}\text { Child } \\
\text { labor }\end{array}$} & $\mathbf{0}$ & 1.000 & 1.112 & 1.199 & 1.293 & 1.397 & 1.510 & 1.634 & 1.769 & 1.915 & 2.073 \\
\hline & $\mathbf{1}$ & 1.000 & 0.000 & 0.000 & 0.000 & 0.000 & 0.000 & 0.000 & 0.000 & 0.000 & 0.000 \\
\hline & 3 & 1.000 & 1.118 & 1.211 & 1.324 & 1.306 & 1.337 & 1.450 & 1.606 & 1.777 & 1.962 \\
\hline & 4 & 1.000 & 0.458 & 0.375 & 0.441 & 0.514 & 0.595 & 0.686 & 0.787 & 0.899 & 1.022 \\
\hline \multirow{4}{*}{$\begin{array}{l}\text { Unskilled } \\
\text { labor }\end{array}$} & 0 & 1.000 & 1.196 & 1.414 & 1.648 & 1.899 & 2.168 & 2.456 & 2.764 & 3.092 & 3.442 \\
\hline & 1 & 1.000 & 1.199 & 1.400 & 1.607 & 1.831 & 2.071 & 2.331 & 2.609 & 2.908 & 3.228 \\
\hline & 2 & 1.000 & 1.200 & 1.415 & 1.647 & 1.897 & 2.164 & 2.451 & 2.759 & 3.088 & 3.439 \\
\hline & 3 & 1.000 & 1.196 & 1.413 & 1.645 & 1.886 & 2.148 & 2.429 & 2.729 & 3.050 & 3.393 \\
\hline \multirow{2}{*}{$\begin{array}{l}\text { Labor - } \\
\text { not } \\
\text { finished } \\
\text { primary } \\
\text { school }\end{array}$} & 3 & 1.000 & 1.005 & 1.001 & 0.995 & 0.995 & 0.990 & 0.982 & 0.973 & 0.962 & 0.951 \\
\hline & 4 & 1.000 & 1.018 & 1.033 & 1.038 & 1.037 & 1.034 & 1.029 & 1.024 & 1.017 & 1.009 \\
\hline \multirow{5}{*}{$\begin{array}{l}\text { Labor - } \\
\text { not } \\
\text { finished } \\
\text { secondary } \\
\text { school }\end{array}$} & 0 & 1.000 & 1.021 & 1.045 & 1.069 & 1.094 & 1.120 & 1.146 & 1.174 & 1.202 & 1.231 \\
\hline & 1 & 1.000 & 1.019 & 1.047 & 1.078 & 1.111 & 1.145 & 1.180 & 1.216 & 1.253 & 1.291 \\
\hline & 2 & 1.000 & 1.019 & 1.042 & 1.067 & 1.092 & 1.117 & 1.144 & 1.170 & 1.198 & 1.225 \\
\hline & 3 & 1.000 & 1.022 & 1.045 & 1.070 & 1.099 & 1.127 & 1.156 & 1.185 & 1.216 & 1.247 \\
\hline & 4 & 1.000 & 1.029 & 1.056 & 1.086 & 1.117 & 1.150 & 1.184 & 1.218 & 1.254 & 1.290 \\
\hline \multirow{4}{*}{$\begin{array}{l}\text { Labor - } \\
\text { secondary } \\
\text { and } \\
\text { higher } \\
\text { educated }\end{array}$} & 0 & 1.000 & 1.027 & 1.054 & 1.083 & 1.114 & 1.145 & 1.179 & 1.214 & 1.252 & 1.291 \\
\hline & 1 & 1.000 & 1.032 & 1.071 & 1.114 & 1.160 & 1.209 & 1.259 & 1.312 & 1.368 & 1.426 \\
\hline & 2 & 1.000 & 1.033 & 1.061 & 1.089 & 1.118 & 1.149 & 1.181 & 1.215 & 1.250 & 1.287 \\
\hline & 3 & 1.000 & 1.026 & 1.055 & 1.086 & 1.108 & 1.141 & 1.181 & 1.223 & 1.266 & 1.312 \\
\hline \multirow{4}{*}{$\begin{array}{l}\text { Non- } \\
\text { agricultural } \\
\text { capital }\end{array}$} & 1 & 1.000 & 1.036 & 1.074 & 1.115 & 1.160 & 1.207 & 1.259 & 1.314 & 1.374 & 1.438 \\
\hline & 2 & 1.000 & 1.036 & 1.074 & 1.115 & 1.160 & 1.208 & 1.260 & 1.315 & 1.376 & 1.441 \\
\hline & 3 & 1.000 & 1.036 & 1.074 & 1.116 & 1.160 & 1.208 & 1.259 & 1.315 & 1.375 & 1.439 \\
\hline & 4 & 1.000 & 1.036 & 1.074 & 1.116 & 1.160 & 1.208 & 1.259 & 1.315 & 1.374 & 1.439 \\
\hline \multirow{5}{*}{ Land } & 0 & 1.000 & 1.035 & 1.071 & 1.109 & 1.148 & 1.188 & 1.229 & 1.272 & 1.317 & 1.363 \\
\hline & 1 & 1.000 & 1.035 & 1.071 & 1.109 & 1.148 & 1.188 & 1.229 & 1.272 & 1.317 & 1.363 \\
\hline & 2 & 1.000 & 1.035 & 1.071 & 1.109 & 1.148 & 1.188 & 1.229 & 1.272 & 1.317 & 1.363 \\
\hline & 3 & 1.000 & 1.035 & 1.071 & 1.109 & 1.148 & 1.188 & 1.229 & 1.272 & 1.317 & 1.363 \\
\hline & 4 & 1.000 & 1.035 & 1.071 & 1.109 & 1.148 & 1.188 & 1.229 & 1.272 & 1.317 & 1.363 \\
\hline
\end{tabular}


nuts, sugar and the trade sector itself). These seem to be very sensitive to any change in the structure of factor supply mainly due to their specific combination of land intensity and rather high skilled labor demand compared to domestically used agriculture. Hence, higher land rent and growing demand for high skilled labor in education hit these sectors twice, while a higher supply of children and unskilled labor is not beneficial to them.

Non-agricultural sectors are generally less sensitive to changes in schooling provision compared to agricultural sectors. In agriculture and food processing we find significant differences between the scenarios. Most agricultural products, as well as hunting, forestry and fishing, experience an additional production boom in scenarios 1 and 4, whereas the opposite is true for maize, other crops and other staple food which are better off in the baseline without additional schooling. These are the main staple food sectors that suffer from the relative scarcity of land.

From a distributional perspective we see that investments in the educational system are clearly poverty reducing and lead to a more even income distribution (see table 7 ). Rural households benefit because land rents increase and thus they earn more. Households with a high-skilled head are better off in the baseline scenario and in scenario 2, where high skilled labor is relatively scarce, whereas poor and unskilled households are better off in the high investment scenarios. These households, who start from a very low endowment with human capital, accumulate relatively more human capital and thus benefit more from higher school provision. The most pro-poor scenario is scenario 4 which combines high schooling provision and the outside option of child labor and thus allows households to accumulate more human capital while still earning income from child labor as well. 
Table 7: Results: Household income, base year $=1$

\begin{tabular}{|c|c|c|c|c|c|c|c|c|c|c|c|}
\hline Household group & Scenario & 2001 & 2002 & 2003 & 2004 & 2005 & 2006 & 2007 & 2008 & 2009 & 2010 \\
\hline rural, & $\mathbf{0}$ & 1.000 & 1.038 & 1.081 & 1.127 & 1.176 & 1.229 & 1.285 & 1.346 & 1.411 & 1.481 \\
\hline below & $\mathbf{1}$ & 1.000 & 1.026 & 1.076 & 1.125 & 1.178 & 1.234 & 1.293 & 1.356 & 1.422 & 1.492 \\
\hline food & 2 & 1.000 & 1.031 & 1.076 & 1.122 & 1.171 & 1.224 & 1.282 & 1.343 & 1.409 & 1.480 \\
\hline poverty & 3 & 1.000 & 1.037 & 1.080 & 1.127 & 1.182 & 1.234 & 1.293 & 1.354 & 1.420 & 1.490 \\
\hline line & 4 & 1.000 & 1.036 & 1.083 & 1.131 & 1.183 & 1.238 & 1.297 & 1.359 & 1.425 & 1.495 \\
\hline rural, & $\mathbf{0}$ & 1.000 & 1.036 & 1.077 & 1.122 & 1.170 & 1.221 & 1.276 & 1.335 & 1.399 & 1.467 \\
\hline between & $\mathbf{1}$ & 1.000 & 1.025 & 1.073 & 1.121 & 1.171 & 1.225 & 1.282 & 1.342 & 1.407 & 1.474 \\
\hline food and & 2 & 1.000 & 1.030 & 1.073 & 1.118 & 1.166 & 1.218 & 1.273 & 1.333 & 1.398 & 1.468 \\
\hline basic & 3 & 1.000 & 1.035 & 1.077 & 1.122 & 1.175 & 1.225 & 1.282 & 1.342 & 1.405 & 1.474 \\
\hline needs line & 4 & 1.000 & 1.033 & 1.079 & 1.125 & 1.175 & 1.228 & 1.285 & 1.345 & 1.409 & 1.476 \\
\hline \multirow{5}{*}{$\begin{array}{l}\text { rural, } \\
\text { uneducated }\end{array}$} & $\mathbf{0}$ & 1.000 & 1.037 & 1.083 & 1.133 & 1.189 & 1.249 & 1.315 & 1.387 & 1.465 & 1.549 \\
\hline & 1 & 1.000 & 1.004 & 1.063 & 1.121 & 1.184 & 1.251 & 1.322 & 1.398 & 1.479 & 1.565 \\
\hline & 2 & 1.000 & 1.011 & 1.062 & 1.114 & 1.170 & 1.232 & 1.299 & 1.372 & 1.451 & 1.537 \\
\hline & 3 & 1.000 & 1.036 & 1.082 & 1.134 & 1.202 & 1.262 & 1.331 & 1.403 & 1.482 & 1.567 \\
\hline & 4 & 1.000 & 1.041 & 1.096 & 1.150 & 1.210 & 1.274 & 1.343 & 1.417 & 1.496 & 1.580 \\
\hline \multirow{5}{*}{$\begin{array}{l}\text { rural, not } \\
\text { finished } \\
\text { primary } \\
\text { school }\end{array}$} & $\mathbf{0}$ & 1.000 & 1.034 & 1.074 & 1.117 & 1.164 & 1.214 & 1.268 & 1.325 & 1.388 & 1.454 \\
\hline & $\mathbf{1}$ & 1.000 & 1.022 & 1.068 & 1.110 & 1.157 & 1.206 & 1.258 & 1.313 & 1.372 & 1.435 \\
\hline & 2 & 1.000 & 1.028 & 1.070 & 1.114 & 1.161 & 1.212 & 1.267 & 1.326 & 1.390 & 1.459 \\
\hline & 3 & 1.000 & 1.033 & 1.073 & 1.117 & 1.164 & 1.212 & 1.267 & 1.324 & 1.385 & 1.451 \\
\hline & 4 & 1.000 & 1.031 & 1.072 & 1.114 & 1.160 & 1.208 & 1.260 & 1.316 & 1.375 & 1.438 \\
\hline \multirow{5}{*}{$\begin{array}{l}\text { rural, not } \\
\text { finished } \\
\text { secondary } \\
\text { school }\end{array}$} & 0 & 1.000 & 1.032 & 1.068 & 1.106 & 1.146 & 1.190 & 1.236 & 1.285 & 1.338 & 1.394 \\
\hline & 1 & 1.000 & 1.026 & 1.065 & 1.103 & 1.143 & 1.186 & 1.231 & 1.280 & 1.332 & 1.387 \\
\hline & 2 & 1.000 & 1.030 & 1.067 & 1.105 & 1.145 & 1.189 & 1.235 & 1.285 & 1.339 & 1.396 \\
\hline & 3 & 1.000 & 1.031 & 1.067 & 1.106 & 1.146 & 1.189 & 1.236 & 1.285 & 1.337 & 1.393 \\
\hline & 4 & 1.000 & 1.031 & 1.067 & 1.103 & 1.144 & 1.187 & 1.232 & 1.281 & 1.333 & 1.388 \\
\hline \multirow{5}{*}{$\begin{array}{l}\text { rural, } \\
\text { secondary } \\
\text { or higher } \\
\text { educated }\end{array}$} & 0 & 1.000 & 1.032 & 1.065 & 1.097 & 1.131 & 1.166 & 1.202 & 1.241 & 1.281 & 1.324 \\
\hline & 1 & 1.000 & 1.039 & 1.068 & 1.092 & 1.119 & 1.148 & 1.178 & 1.210 & 1.245 & 1.282 \\
\hline & 2 & 1.000 & 1.042 & 1.073 & 1.105 & 1.138 & 1.174 & 1.211 & 1.250 & 1.292 & 1.336 \\
\hline & 3 & 1.000 & 1.032 & 1.064 & 1.096 & 1.120 & 1.154 & 1.190 & 1.227 & 1.265 & 1.307 \\
\hline & 4 & 1.000 & 1.026 & 1.052 & 1.078 & 1.107 & 1.137 & 1.169 & 1.203 & 1.239 & 1.277 \\
\hline \multirow{5}{*}{$\begin{array}{l}\text { urban, } \\
\text { below } \\
\text { food } \\
\text { poverty } \\
\text { line }\end{array}$} & 0 & 1.000 & 1.030 & 1.063 & 1.098 & 1.136 & 1.175 & 1.218 & 1.263 & 1.311 & 1.362 \\
\hline & 1 & 1.000 & 1.029 & 1.063 & 1.099 & 1.138 & 1.179 & 1.223 & 1.270 & 1.319 & 1.373 \\
\hline & 2 & 1.000 & 1.030 & 1.063 & 1.098 & 1.135 & 1.175 & 1.217 & 1.262 & 1.310 & 1.361 \\
\hline & 3 & 1.000 & 1.030 & 1.063 & 1.098 & 1.138 & 1.177 & 1.220 & 1.266 & 1.315 & 1.367 \\
\hline & 4 & 1.000 & 1.033 & 1.066 & 1.101 & 1.140 & 1.181 & 1.225 & 1.272 & 1.321 & 1.374 \\
\hline \multirow{5}{*}{$\begin{array}{l}\text { urban, } \\
\text { between } \\
\text { food and } \\
\text { basic } \\
\text { needs line }\end{array}$} & 0 & 1.000 & 1.038 & 1.079 & 1.123 & 1.170 & 1.221 & 1.275 & 1.333 & 1.395 & 1.462 \\
\hline & 1 & 1.000 & 1.025 & 1.072 & 1.120 & 1.172 & 1.226 & 1.285 & 1.347 & 1.413 & 1.484 \\
\hline & 2 & 1.000 & 1.027 & 1.070 & 1.114 & 1.162 & 1.212 & 1.266 & 1.324 & 1.386 & 1.453 \\
\hline & 3 & 1.000 & 1.038 & 1.079 & 1.124 & 1.179 & 1.230 & 1.285 & 1.344 & 1.408 & 1.475 \\
\hline & 4 & 1.000 & 1.044 & 1.087 & 1.133 & 1.184 & 1.237 & 1.295 & 1.356 & 1.421 & 1.491 \\
\hline \multirow{5}{*}{$\begin{array}{l}\text { urban, } \\
\text { uneducated }\end{array}$} & 0 & 1.000 & 1.027 & 1.059 & 1.094 & 1.133 & 1.174 & 1.220 & 1.269 & 1.322 & 1.379 \\
\hline & 1 & 1.000 & 1.011 & 1.048 & 1.089 & 1.132 & 1.179 & 1.230 & 1.284 & 1.342 & 1.403 \\
\hline & 2 & 1.000 & 1.013 & 1.046 & 1.082 & 1.120 & 1.162 & 1.207 & 1.256 & 1.309 & 1.366 \\
\hline & 3 & 1.000 & 1.027 & 1.059 & 1.094 & 1.141 & 1.184 & 1.231 & 1.281 & 1.336 & 1.394 \\
\hline & 4 & 1.000 & 1.037 & 1.073 & 1.111 & 1.153 & 1.198 & 1.247 & 1.300 & 1.356 & 1.417 \\
\hline \multirow{5}{*}{$\begin{array}{l}\text { urban, not } \\
\text { finished } \\
\text { primary } \\
\text { school }\end{array}$} & 0 & 1.000 & 1.025 & 1.055 & 1.087 & 1.122 & 1.159 & 1.200 & 1.243 & 1.289 & 1.338 \\
\hline & 1 & 1.000 & 1.022 & 1.053 & 1.082 & 1.114 & 1.148 & 1.185 & 1.225 & 1.267 & 1.313 \\
\hline & 2 & 1.000 & 1.025 & 1.055 & 1.088 & 1.123 & 1.161 & 1.202 & 1.246 & 1.293 & 1.343 \\
\hline & 3 & 1.000 & 1.024 & 1.054 & 1.086 & 1.118 & 1.154 & 1.195 & 1.237 & 1.282 & 1.330 \\
\hline & 4 & 1.000 & 1.027 & 1.055 & 1.083 & 1.115 & 1.150 & 1.187 & 1.227 & 1.270 & 1.316 \\
\hline \multirow{5}{*}{$\begin{array}{l}\text { urban, not } \\
\text { finished } \\
\text { secondary } \\
\text { school }\end{array}$} & 0 & 1.000 & 1.028 & 1.059 & 1.093 & 1.128 & 1.166 & 1.207 & 1.250 & 1.296 & 1.346 \\
\hline & 1 & 1.000 & 1.025 & 1.057 & 1.086 & 1.119 & 1.154 & 1.191 & 1.231 & 1.275 & 1.321 \\
\hline & 2 & 1.000 & 1.028 & 1.060 & 1.093 & 1.129 & 1.168 & 1.209 & 1.253 & 1.300 & 1.351 \\
\hline & 3 & 1.000 & 1.027 & 1.059 & 1.092 & 1.123 & 1.161 & 1.202 & 1.244 & 1.289 & 1.338 \\
\hline & 4 & 1.000 & 1.029 & 1.058 & 1.087 & 1.120 & 1.155 & 1.193 & 1.233 & 1.277 & 1.323 \\
\hline \multirow{5}{*}{$\begin{array}{l}\text { urban, } \\
\text { secondary } \\
\text { or higher } \\
\text { educated }\end{array}$} & $\mathbf{0}$ & 1.000 & 1.031 & 1.070 & 1.109 & 1.149 & 1.192 & 1.237 & 1.284 & 1.335 & 1.389 \\
\hline & 1 & 1.000 & 1.027 & 1.064 & 1.088 & 1.116 & 1.146 & 1.177 & 1.211 & 1.247 & 1.286 \\
\hline & 2 & 1.000 & 1.034 & 1.075 & 1.114 & 1.156 & 1.200 & 1.248 & 1.298 & 1.352 & 1.410 \\
\hline & 3 & 1.000 & 1.030 & 1.068 & 1.106 & 1.131 & 1.172 & 1.216 & 1.259 & 1.305 & 1.354 \\
\hline & 4 & 1.000 & 1.021 & 1.050 & 1.075 & 1.105 & 1.137 & 1.170 & 1.205 & 1.243 & 1.284 \\
\hline
\end{tabular}




\section{Conclusion and policy implications}

We have shown how human capital accumulation can be modeled in detailed manner in a developing country CGE model. By disaggregating skilled and semi-skilled labor into the raw labor force and the human capital and by modeling schooling, i.e. educational production, explicitly, we add a number of aspects that have so far been treated indirectly in comparable studies. We are able to model the endogenous choice of skill levels, educational demand, opportunity costs of sending children to school and the effects of an increased pupil-teacher ratio.

Using our model to analyze different policy options we confirm a growth and welfare increasing effect from school investments, even though it is rather small, like other authors have shown before. However, a noteworthy effect on macro-economic variables is only reached if increased enrollment is accompanied by both, higher schooling investment and a higher employment of teachers. If both are in place, the majority of children are endogenously sent to school even if mandatory schooling is not enforced. The opposite is true for mandatory schooling without the required resources. In this case we do not find a growth or welfare effect as the positive effect from human capital accumulation is compensated by a negative effect from reduced childrens' production and income as well as reduced pass-rates.

In this study we used a dataset for Tanzania for 2001, which provided enough information on labor and skill disaggregation. However, it could be used with more recent datasets as well as other countries, if datasets with enough details were available. It could then be used to simulate policies beforehand.

The schooling investment policies are especially beneficial for poor households and those with very low skills. These households benefit overproportionally from increased human capital accumulation and thus receive higher income.

We confirm, in accordance with other authors, that capital as well as land might act as constraining factor on the growth effect from increased human capital. Even with the assumption of increasing productivity of both capital and land, we find land to be relatively scarce and thus being paid higher rents compared to all labor classes' wages. This indicates that the new high and semi skilled labor could produce even more if it was equipped with more land or if capital and land productivity would rise. 


\section{References}

Agenor, Pierre-Richard, Bayraktar, Nihal, \& El Aynaoui, Karim. 2008. Roads out of poverty? Assessing the links between aid, public investment, growth, and poverty reduction. Journal of Development Economics, 86(2), 277-295.

Arndt, Channing, Benfica, Rui, Tarp, Finn, Thurlow, James, \& Uaiene, Rafael. 2010. Biofuels, Poverty, and Growth: A Computable General Equilibrium Analysis of Mozambique. Environment and Development Economics, 15(01), 81-105.

Barro, Robert J. 1997. Determinants of economic growth: a cross-country empirical study. The MIT Press.

Barro, Robert J., \& Sala-i-Martin, Xavier. 2003. Economic Growth. 2nd edn. The MIT Press.

Cloutier, Marie-Hélène, Cockburn, John, \& Decaluwé, Bernard. 2008. Education and Poverty in Vietnam: A Computable General Equilibrium Analysis. C I R P E E Working Paper, 08(04).

Dreher, Axel, Nunnenkamp, Peter, \& Thiele, Rainer. 2008. Does aid for education educate children? Evidence from Panel-Data. World Bank Economic Review, 22(2), 291-314.

Gupta, Sanjeev, \& Verhoeven, Marijn. 2001. The efficiency of government expenditure: experiences from Africa. Journal of Policy Modeling, 23(4), 433-467.

Gupta, Sanjeev, Verhoeven, Marijn, \& Tiongson, Erwin R. 1999. Does Higher Government Spending Buy Better Results in Education and Health Care? IMF Working Paper Series, $\mathbf{9 9}(21)$.

Heller, Peter S. 2005. "Pity the Finance Minister": Issues in Managing Substantial Scalingup of Aid Flows. World Economics, 6(4), 69-110.

Jensen, Jesper, \& Tarr, David G. 2011. Deep trade policy options for Armenia : the importance of services, trade facilitation and standards liberalization. Tech. rept. 5662. The World Bank, Washington D.C.

Jung, Hong-Sang, \& Thorbecke, Erik. 2003. The impact of public education expenditure on human capital, growth, and poverty in Tanzania and Zambia: a general equilibrium approach. Journal of Policy Modeling, 25(8), 701-725.

Maisonnave, Hélèn, \& Décaluwé, Bernard. 2010. Politique éducative et marché du travail en Afrique du Sud. Une analyse en EGC. Recherches économiques de Louvain, 76(3), 289-335. 
Markusen, James R. 2004. Multinational firms and the theory of international trade. MIT Press.

Pritchett, Lant. 2001. Where Has All the Education Gone? The World Bank Economic Review, 15(3), $367-391$.

Rutherford, Thomas F. 1999. Applied General Equilibrium Modeling with MPSGE as a GAMS Subsystem: An Overview of the Modeling Framework and Syntax. Computational Economics, 14(1-2), 1-46.

Schultz, T. Paul. 1999. Health and Schooling Investments in Africa. Journal of Economic Perspectives, 13(3), 67-88.

The World Bank. 2005. Tanzania - Primary Education Development Program, Implementation, Completion and Results Report. Tech. rept. 32071. The World Bank, Washington D.C.

The World Bank. 2011. Tanzania - Secondary Educ. Development Program II : P114866 - Implementation Status Results Report: Sequence 02. Tech. rept. ISR2375. The World Bank, Washington D.C.

Thurlow, James. 2004. A Dynamic Computable General Equilibrium (CGE) Model for South Africa: Extending the Static IFPRI Model. Tech. rept. 1-2004. Trade \& Industrial Policy Strategies - TIPS.

Thurlow, James, \& Wobst, Peter. 2003. Poverty-focused Social Accounting Matrices for Tanzania. TMD Discussion Paper, vol. 112. Washington D.C.: International Food Policy Research Institute.

Thurlow, James, \& Wobst, Peter. 2006. Not All Growth is Equally Good for the Poor: The Case of Zambia. Journal of African Economies, 15(4), $603-625$.

Topel, Robert H. 1997. Factor Proportions and Relative Wages: The Supply-Side Determinants of Wage Inequality. The Journal of Economic Perspectives, 11(2), 55-74.

Wobst, Peter, \& Arndt, Channing. 2004. HIV/AIDS and Labor Force Upgrading in Tanzania. World Development, 32(11), 1831-1847. 


\section{A. Data description and parameters}

Table 8: Household and labor classes

\begin{tabular}{l|l|l}
\hline \hline Abbreviation & Description & Classification \\
\hline Households & Rural, below food poverty line & rural, poor \\
HRFBPL & Rural, above food, below basic needs poverty line & rural, poor \\
HRNFPS & Rural, HH head has not finished primary school & rural, non-poor, low-skilled \\
HRNFSS & Rural, HH head has not finished secondary school & rural, non-poor, low-skilled \\
HRSECP & Rural, HH head has not finished primary school & rural, non-poor, high-skilled \\
HUBFPL & Urban, below food poverty line & Urban, poor \\
HUFBPL & Urban, above food, below basic needs poverty line & Urban, poor \\
HUNFPS & Urban, HH head has not finished primary school & Urban, non-poor, low-skilled \\
HUNFSS & Urban, HH head has not finished secondary school & Urban, non-poor, low-skilled \\
HUSECP & Urban, HH head has not finished primary school & Urban, non-poor, high-skilled \\
\hline Labor Classes & & \\
FSUB & Subsistence labor & Unskilled \\
CHILD & Child labor & Unskilled \\
LNON & Adult, no education & Unskilled \\
LNFP & Adult, not finished primary school & Low-skilled \\
LNFS & Adult, not finished secondary school & Low-skilled \\
LSEC & Adult, secondary or higher education & High-skilled \\
\hline \hline
\end{tabular}


Table 9: Production sectors

\begin{tabular}{|c|c|c|}
\hline Sector & Description & Classification \\
\hline MAIZE & Maize & Agricultural, high share home consumption, tradeable \\
\hline PADDY & Paddy rice & Agricultural, medium share home consumption, tradeable \\
\hline OSTF & Other staple food & Agricultural, high share home consumption, tradeable \\
\hline WHEAT & Wheat & Agricultural, low share home consumption, tradeable \\
\hline BEANS & Beans & Agricultural, medium share home consumption, tradeable \\
\hline CEREA & Cereals & Agricultural, medium share home consumption, tradeable \\
\hline OILSE & Oil seed & Agricultural, medium share home consumption, tradeable \\
\hline COTTO & Cotton & Agricultural, no home consumption, tradeable \\
\hline COFFE & Coffee & Agricultural, low share home consumption, tradeable \\
\hline TOBAC & Tobacco & Agricultural, no home consumption, tradeable \\
\hline TEAGR & Tea growing & Agricultural, low share home consumption, tradeable \\
\hline CASHE & Cashew nuts & Agricultural, no home consumption, tradeable \\
\hline SISAL & Sisal & Agricultural, no home consumption, non tradeable \\
\hline SUGAR & Sugar & Agricultural, low share home consumption, tradeable \\
\hline OFRVE & Other fruit and vegetables & Agricultural, medium share home consumption, tradeable \\
\hline OCROP & Other crops & Agricultural, medium share home consumption, tradeable \\
\hline LIVES & Livestock & Agricultural, medium share home consumption, tradeable \\
\hline FISHI & Fishing & Agricultural, low share home consumption, tradeable \\
\hline HUFOR & Hunting and forestry & Agricultural, medium share home consumption, tradeable \\
\hline MININ & Mining & Manufacturing, no home consumption, tradeable \\
\hline MEATD & Meat and dairy products & Manufacturing, medium share home consumption, tradeable \\
\hline GRAIN & Grain milling & Manufacturing, no home consumption, tradeable \\
\hline PFOOD & Processed food & Manufacturing, low share home consumption, tradeable \\
\hline BEVER & Beverages & Manufacturing, low share home consumption, tradeable \\
\hline CLOTH & Clothing & Manufacturing, no home consumption, tradeable \\
\hline WOODP & Wood and paper & Manufacturing, no home consumption, tradeable \\
\hline CHEMI & Chemistry, fertilizer and refinery & Manufacturing, no home consumption, tradeable \\
\hline RUPLA & Rubber and plastic & Manufacturing, no home consumption, tradeable \\
\hline GLASS & Glass & Manufacturing, no home consumption, tradeable \\
\hline METAL & Metallurgy & Manufacturing, no home consumption, tradeable \\
\hline EQUIP & Equipment & Manufacturing, no home consumption, tradeable \\
\hline UTILI & Utilities & Manufacturing, no home consumption, non tradeable \\
\hline CONST & Construction & Manufacturing, no home consumption, non tradeable \\
\hline TRADE & Trade & Services, no home consumption, non tradeable \\
\hline TRANS & Transport & Services, no home consumption, tradeable \\
\hline ESTAT & Real estate & Services, medium share home consumption, non tradeable \\
\hline ADMIN & Public services, administration & Services, no home consumption, tradeable \\
\hline PRIVS & Other private services & Services, no home consumption, tradeable \\
\hline
\end{tabular}




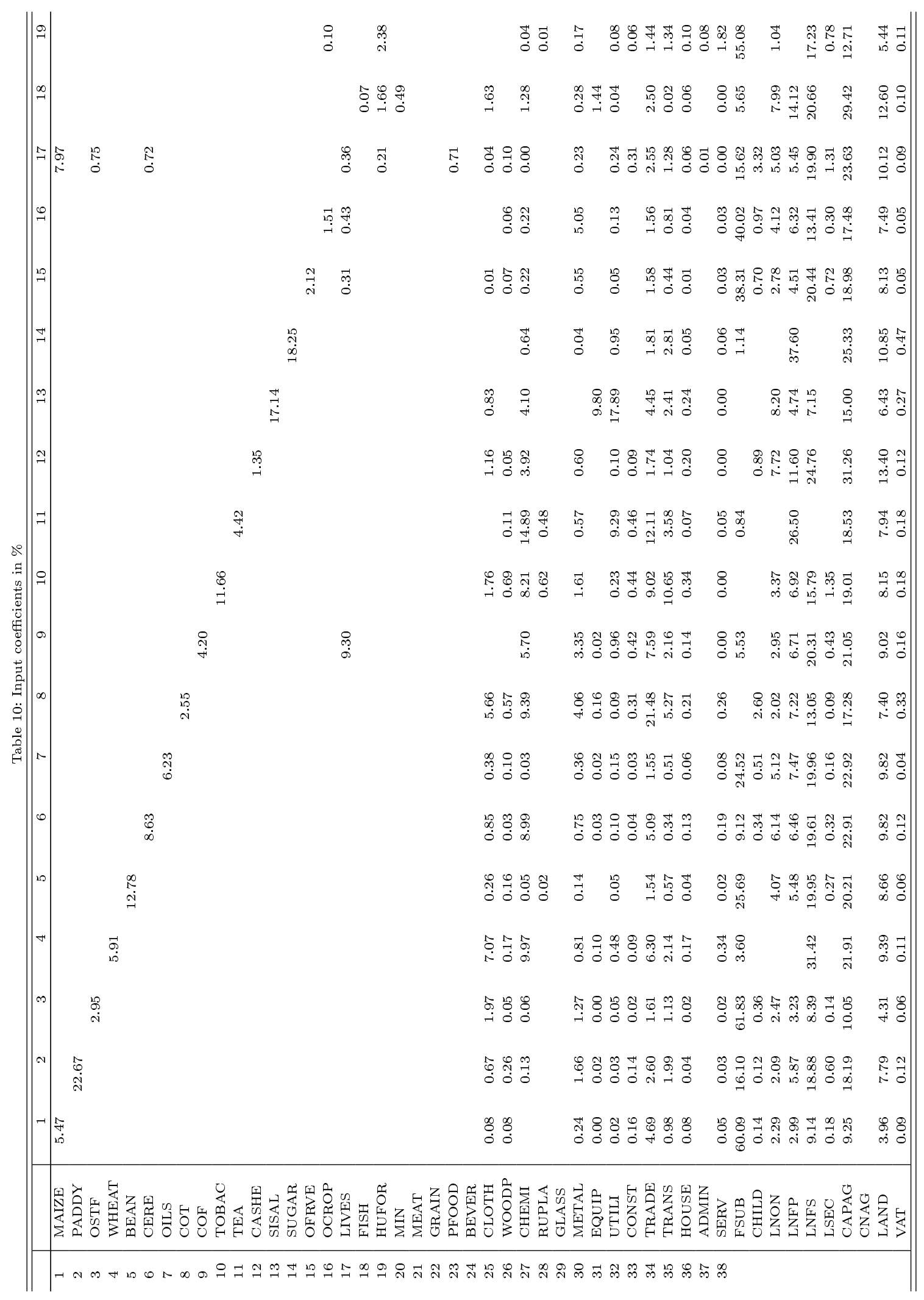




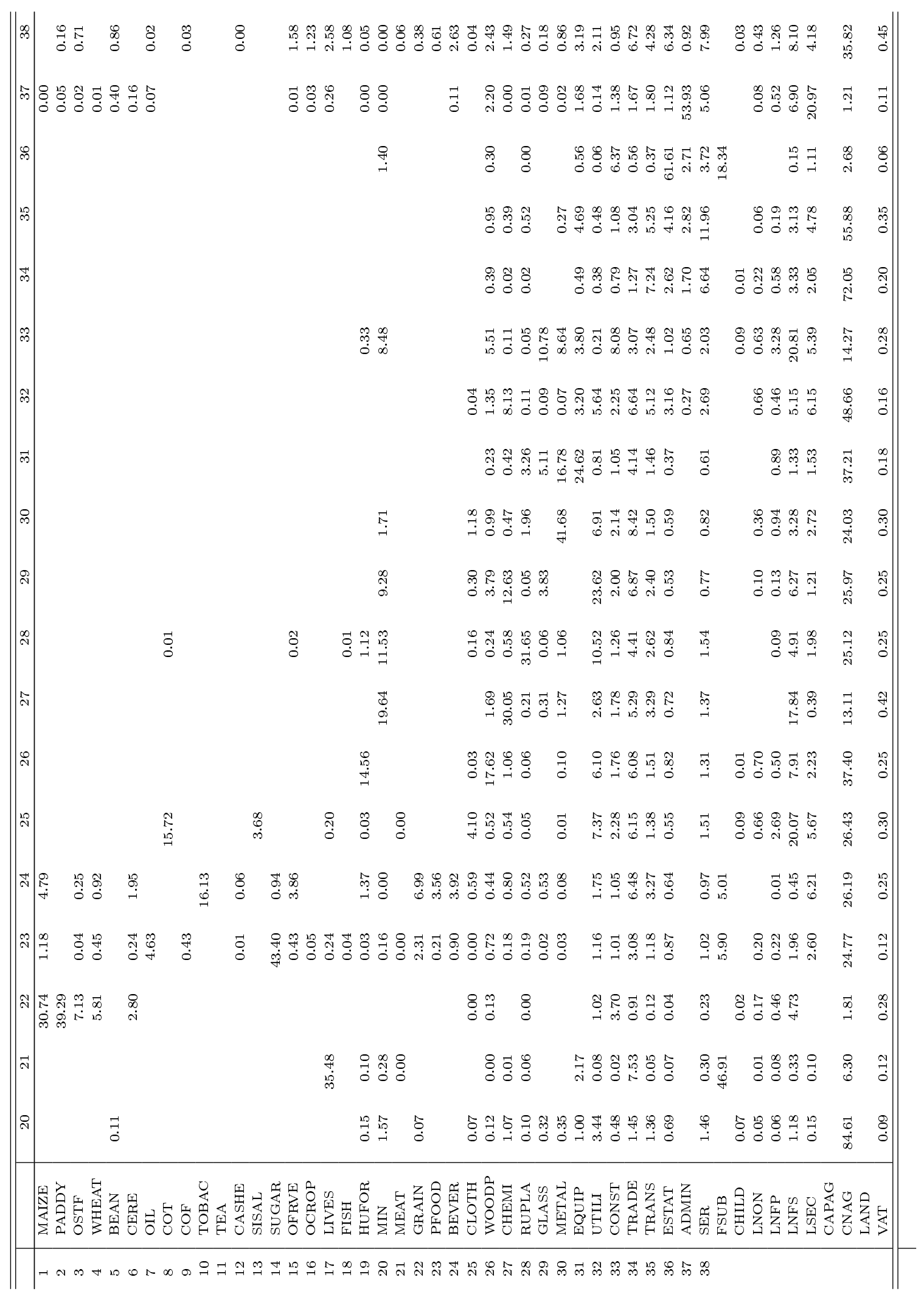


Table 11: Armington elasticities

\begin{tabular}{|c|c|c|c|}
\hline sector & $\begin{array}{l}\rho_{i}^{s} \\
\text { Import } \quad \text { substitu- } \\
\text { tion }\end{array}$ & $\begin{array}{l}\rho_{i}^{t} \\
\text { Export } \quad \text { transfor- } \\
\text { mation }\end{array}$ & $\begin{array}{l}\tau_{i} \\
\text { Home-market } \\
\text { transformation }\end{array}$ \\
\hline MAIZE & 2.0 & 2.0 & 4.0 \\
\hline PADDY & 2.0 & 2.0 & 4.0 \\
\hline OSTF & 2.0 & 2.0 & 4.0 \\
\hline WHEAT & 2.0 & 2.0 & 2.0 \\
\hline BEANS & 2.0 & 2.0 & 4.0 \\
\hline CEREA & 2.0 & 2.0 & 2.0 \\
\hline OILSE & 2.0 & 2.0 & 4.0 \\
\hline COTTO & 1.5 & 4.0 & 2.0 \\
\hline COFFE & 1.5 & 4.0 & 2.0 \\
\hline TOBAC & 1.5 & 4.0 & 2.0 \\
\hline TEAGR & 1.5 & 4.0 & 2.0 \\
\hline CASHE & 1.5 & 4.0 & 2.0 \\
\hline SISAL & 1.5 & 4.0 & 2.0 \\
\hline SUGAR & 1.5 & 4.0 & 2.0 \\
\hline OFRVE & 1.5 & 4.0 & 2.0 \\
\hline OCROP & 1.5 & 4.0 & 2.0 \\
\hline LIVES & 0.5 & 0.5 & 4.0 \\
\hline FISHI & 0.5 & 0.5 & 4.0 \\
\hline HUFOR & 0.5 & 0.5 & 4.0 \\
\hline MININ & 1.5 & 4.0 & 0.1 \\
\hline MEATD & 0.5 & 0.5 & 4.0 \\
\hline GRAIN & 1.5 & 4.0 & 2.0 \\
\hline PFOOD & 1.5 & 1.5 & 2.0 \\
\hline BEVER & 1.5 & 1.5 & 2.0 \\
\hline CLOTH & 1.5 & 1.5 & 0.5 \\
\hline WOODP & 1.5 & 1.5 & 0.5 \\
\hline CHEMI & 0.2 & 0.2 & 0.2 \\
\hline RUPLA & 1.0 & 1.0 & 0.2 \\
\hline GLASS & 1.0 & 1.0 & 0.2 \\
\hline METAL & 1.0 & 1.0 & 0.2 \\
\hline EQUIP & 1.0 & 1.0 & 0.2 \\
\hline UTILI & 1.0 & 1.0 & 0.2 \\
\hline CONST & 1.0 & 1.0 & 0.2 \\
\hline TRADE & 0.2 & 0.2 & 0.1 \\
\hline TRANS & 1.0 & 1.0 & 0.1 \\
\hline ESTAT & 0.2 & 0.2 & 0.2 \\
\hline ADMIN & 0.2 & 0.2 & 0.2 \\
\hline PRIVS & 0.2 & 0.2 & 0.2 \\
\hline
\end{tabular}




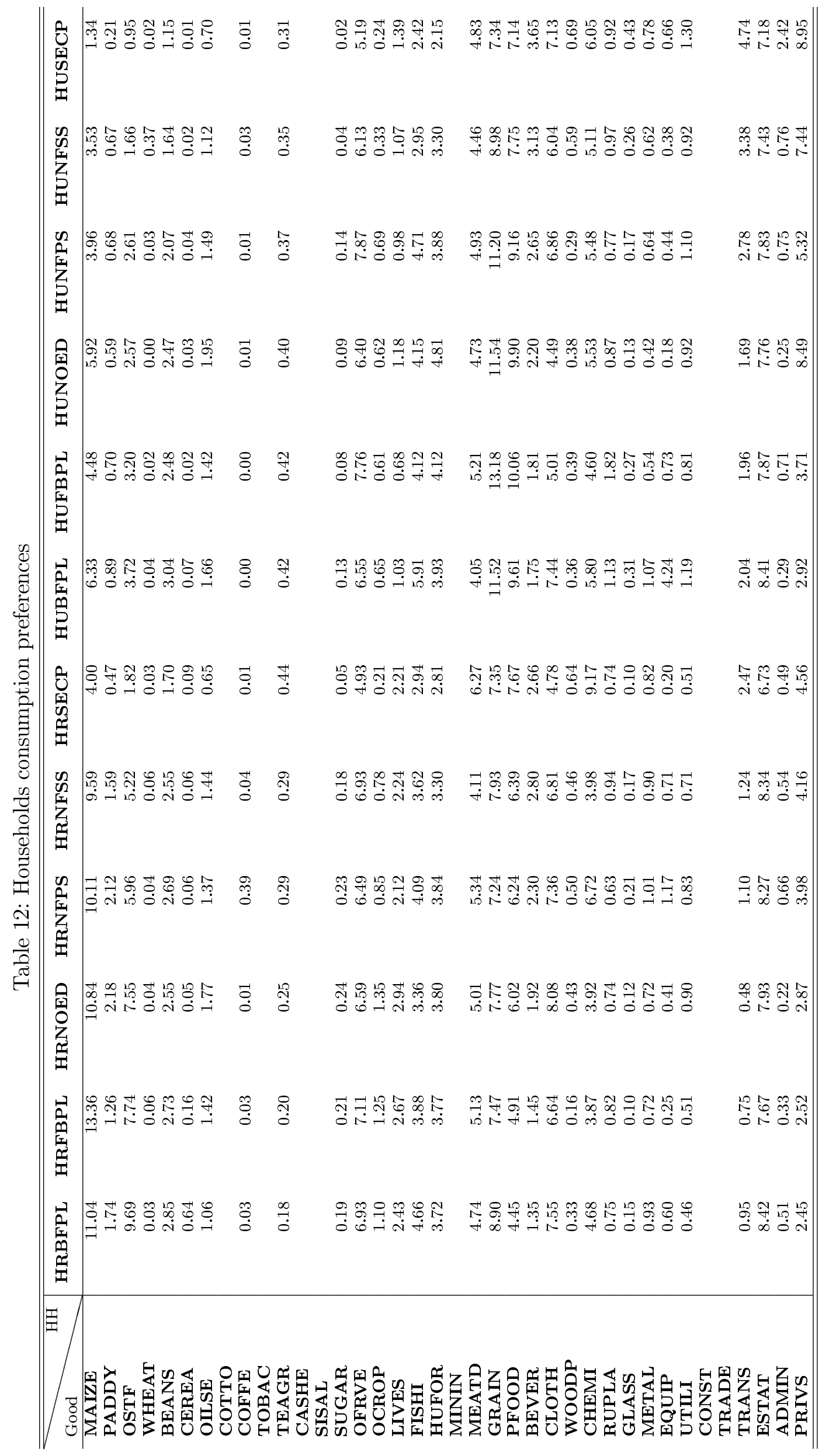




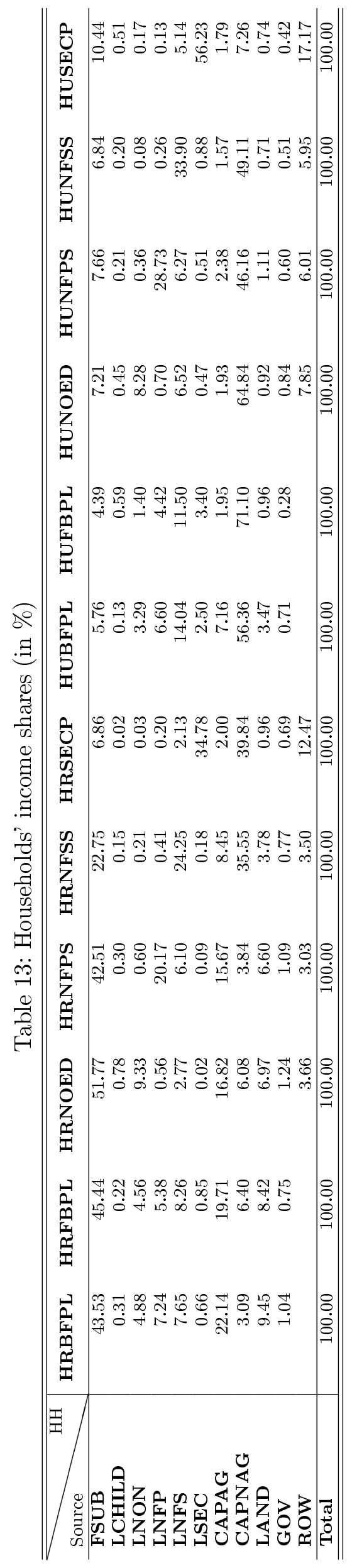




\section{B. Skilled labor disaggregation}

Social Accounting Matrices commonly report values for the inputs in production not the quantities and prices separately. In CGE applications the convention is usually that the initial prices are all set to unity such that values and quantities are equal. Thus from the SAM information on the wage premium for human capital cannot be retrieved, however we follow a modeling procedure which discriminates between the number of (physical) workers and the value of their human capital. Hence we had to combine the SAM data with other data in order to find out the number of skilled workers instead of their value and this has to be done for all different skill classes.

Fortunately the IFPRI SAM uses labor force data from the Labour Force Survey $2000 / 2001^{11}$ and thus a mapping of the number of workers and the value of these workers is available. Thurlow \& Wobst [See 2003, p.27] Please note, this mapping is only available for the whole labor force not on a sectoral basis, hence we are only able to make an average decomposition not a sector-specific decomposition.

We decompose the values from the SAM into the value of the physical, unskilled workers and the value of their human capital. We first calculate the average wage of an unskilled worker:

$$
w_{L N O N}=\frac{\sum_{i} D_{i}^{L N O N}(S A M)}{n_{L N O N}(L F S)}
$$

For each skilled labor class (s) we then calculate the implicit value of the physical workers in this skill class over all sectors:

$$
\sum_{i} D_{(i, s)}^{L N O N}=n_{s}(L F S) \cdot w_{L N O N}
$$

Hence, the value of human capital for each skill class (s) in all sectors (i)is retrieved as:

$$
\sum_{i} D_{i, s}^{H C}=\sum_{i} D_{i}^{L s}-\sum_{i} D_{(i, s)}^{L N O N}
$$

Having retrieved the aggregate numbers for the implicit values of workers and human capital for each skill class (s), we are now able to calculate the shares reported in table 1. These shares are used to calculate the endowments with human capital and unskilled workers for each household type $h$ and for the calibration of the production functions for skilled workers of the different skill levels. Thus we have finally decomposed demand and supply of labor of any skill class into unskilled workers and a certain amount of human capital.

\footnotetext{
${ }^{11}$ published by the Tanzanian National Bureau of Statistics (2002).
} 


\section{Robustness}

As we have a very high degree of disaggregation both in production sectors and production factors, it is very important to test whether the results are robust with respect to the assumed elasticities both in the production function as well as in the Armington aggregation. In order to test this robustness, we have run a series of 1000 simulations in which we have drawn these elasticities randomly from the intervals shown in table $14 .{ }^{12}$ Given the dynamic structure of the model as well as the high degree of disaggregation these simulations produce a high amount of data. We focus here on presenting the results for the macroeconomic aggregates. However, all results presented above lie within a $95 \%$ confidence interval based on all 1000 simulations.

Table 14 shows the intervals from which the elasticities have been drawn. It is obvious that we include a very high variation for the elasticities. We generate the elasticities using a random number generator, we cannot allow negative numbers, and in the Armington function elasticities of 0 are not possible, either. Apart from these limitations we allow any combination of elasticities.

Table 14: Distribution of elasticities

\begin{tabular}{l|c|c|c}
\hline \hline Elasticity & Value in simulations & Min in Robustness checks & Max in Robustness checks \\
\hline Production function & 0 & & \\
$\sigma_{c a p}$ & 0.5 & 0.0 & 1.5 \\
$\sigma_{v a}$ & 0.5 & 0.0 & 2.0 \\
$\sigma_{l a b}$ & 1 & 0.0 & 2.0 \\
$\sigma_{h s k l}$ & 2 & 0.2 & 3.0 \\
$\sigma_{l s k l}$ & 8 & 0.5 & 5.0 \\
$\sigma_{\text {non }}$ & 2.0 & 16.0 \\
\hline Armington aggregation & $0.2-2.0$ & 0.00001 & 6.0 \\
$\rho^{s}$ & $0.2-4.0$ & 0.00001 & 6.0 \\
$\rho^{t}$ & & \\
\hline \hline
\end{tabular}

Table 15 presents the relative deviation between our results reported in the respective section and the maximum and minimum values retrieved for the respective variables in the robustness checks. We calculate the deviation of the maximum (minimum) value from the value reported in our result-section relative to the result value itself. Most results spread only within an interval of less than $1 \%$ around the results originally presented above. Thus, we consider our results very robust with respect to the elasticity parameters.

The results for the Hicks equivalent welfare measure are slightly less robust than those for GDP and educational production. GDP and educational production produce fairly robust results, especially in the case of educational production where the scenarios differ

\footnotetext{
${ }^{12}$ Jensen \& Tarr [2011] follow a comparable procedure for robustness tests.
} 
substantially, the deviation may be considered insignificant.

On the macroeconomic level, we find noteworthy variance only for price variables not for quantity variables. Hence, the changes in the substitutability between factors or between markets are absorbed by prices and have only marginal real effects. Prices in CGE models in general only reflect relative price evolution compared to a numéraire good (the trade basket's price on world markets in our case). Thus, prices in general should be interpreted with some caution. We do not interpret the price results here and the real effects shown above seem to be quite robust concerning the choice of elasticities. At one point in our model a price effect is crucial, though: the price for human capital influences households' demand for education. However, the price for education is (also in the robustness simulations) closely linked to the price for human capital and thus, the demand-increasing effect of a specifically high price of human capital is compensated by a demand-decreasing effect of the price for education. The educational production is thus not affected as shown above in table 15 .

Table 15: Relative deviation of reported results from maximum and minimum retrieved in robustness checks

\begin{tabular}{|c|c|c|c|c|c|c|c|c|c|c|c|c|}
\hline Variable & $\begin{array}{l}\text { Indi- } \\
\text { cator }\end{array}$ & $\begin{array}{l}\text { Sce- } \\
\text { nario }\end{array}$ & 2001 & 2002 & 2003 & 2004 & 2005 & 2006 & 2007 & 2008 & 2009 & 2010 \\
\hline \multirow{8}{*}{ GDP } & \multirow{5}{*}{ Max-dev } & $\mathbf{1}$ & 0.000 & 0.000 & 0.000 & 0.000 & 0.001 & 0.001 & 0.002 & 0.002 & 0.003 & 0.004 \\
\hline & & 2 & 0.000 & 0.000 & 0.000 & 0.000 & 0.000 & 0.000 & 0.000 & 0.000 & 0.001 & 0.001 \\
\hline & & 3 & 0.000 & 0.000 & 0.000 & 0.000 & 0.000 & 0.000 & 0.001 & 0.001 & 0.002 & 0.002 \\
\hline & & 4 & 0.000 & 0.000 & 0.000 & 0.000 & 0.000 & 0.001 & 0.001 & 0.002 & 0.003 & 0.004 \\
\hline & & 1 & 0.000 & 0.000 & 0.000 & 0.001 & 0.001 & 0.002 & 0.004 & 0.005 & 0.009 & 0.012 \\
\hline & \multirow{3}{*}{ Min-dev } & 2 & 0.000 & 0.000 & 0.000 & 0.001 & 0.001 & 0.002 & 0.003 & 0.006 & 0.009 & 0.013 \\
\hline & & 3 & 0.000 & 0.000 & 0.000 & 0.001 & 0.003 & 0.003 & 0.004 & 0.004 & 0.006 & 0.009 \\
\hline & & 4 & 0.000 & 0.000 & 0.000 & 0.001 & 0.001 & 0.002 & 0.003 & 0.005 & 0.009 & 0.013 \\
\hline \multirow{4}{*}{ Welfare } & \multirow{4}{*}{ Max-dev } & $\mathbf{1}$ & 0.000 & 0.001 & 0.001 & 0.001 & 0.001 & 0.002 & 0.002 & 0.003 & 0.003 & 0.004 \\
\hline & & 2 & 0.000 & 0.001 & 0.001 & 0.001 & 0.002 & 0.002 & 0.003 & 0.004 & 0.005 & 0.006 \\
\hline & & 3 & 0.000 & 0.001 & 0.001 & 0.002 & 0.003 & 0.003 & 0.004 & 0.005 & 0.005 & 0.006 \\
\hline & & 4 & 0.000 & 0.004 & 0.003 & 0.002 & 0.003 & 0.004 & 0.004 & 0.005 & 0.006 & 0.007 \\
\hline \multirow{8}{*}{$\begin{array}{l}\text { Educa- } \\
\text { tional } \\
\text { produc- } \\
\text { tion }\end{array}$} & \multirow{4}{*}{ Max-dev } & $\mathbf{1}$ & 0.000 & 0.000 & 0.000 & 0.000 & 0.000 & 0.000 & 0.000 & 0.000 & 0.000 & 0.000 \\
\hline & & 2 & 0.000 & 0.000 & 0.000 & 0.000 & 0.000 & 0.000 & 0.000 & 0.000 & 0.000 & 0.000 \\
\hline & & 3 & 0.000 & 0.000 & 0.000 & 0.000 & 0.000 & 0.000 & 0.000 & 0.000 & 0.000 & 0.000 \\
\hline & & 4 & 0.000 & 0.000 & 0.000 & 0.000 & 0.000 & 0.000 & 0.001 & 0.001 & 0.001 & 0.001 \\
\hline & \multirow{4}{*}{ Min-dev } & 1 & 0.000 & 0.000 & 0.000 & 0.000 & 0.000 & 0.001 & 0.001 & 0.001 & 0.001 & 0.001 \\
\hline & & 2 & 0.000 & 0.000 & 0.000 & 0.000 & 0.000 & 0.000 & 0.000 & 0.000 & 0.000 & 0.000 \\
\hline & & 3 & 0.000 & 0.000 & 0.000 & 0.000 & 0.001 & 0.001 & 0.001 & 0.001 & 0.001 & 0.001 \\
\hline & & 4 & 0.000 & 0.000 & 0.000 & 0.000 & 0.000 & 0.001 & 0.001 & 0.001 & 0.001 & 0.001 \\
\hline
\end{tabular}

We see from our robustness checks that the aggregate variable results are quite robust with respect to massive changes in the elasticities in production and trade. However, on the sectoral level, we find some sectors which are very sensitive to the elasticity set, namely coffee, fishing, hunting/forestry and private services. As the anomalities also occur in the base year before any schooling policy is in place and are also present in all different counterfactuals, we are sure that this result is not specific to our policy simu- 
lations and thus the other results for the different scenarios are still valid. However, the non-robustness of disaggregate results on the sectoral level sheds light on the fact that more reliable information on sector specific elasticities would be a valuable improvement of most developing country CGEs with high degrees of disaggregation.

Table 16 summarizes the sectoral robustness results. We report two criteria for robustness here: Whether or not the result of our simulations with the initital elasticity set lies within a $95 \%$ confidence interval computed based on the robustness simulations and whether our result does not deviate by more than $5 \%$ from the minimum and maximum values found in the robustness simulations. A "+" in table 16 indicates that the criterion is fulfilled for the respective sector in all scenarios, a "(+)" means that it is fulfilled in three out of the four scenarios.

Table 16: Summary sectoral robustness

\begin{tabular}{l|c|c}
\hline \hline Sector & 95\%-Criterion & 5\%-Deviation-Criterion \\
\hline MAIZE & + & $(+)$ \\
PADDY & + & - \\
OSTF & + & - \\
WHEAT & + & - \\
BEANS & + & - \\
CEREA & + & + \\
OILSE & + & + \\
COTTO & + & - \\
COFFE & - & - \\
TOBAC & + & - \\
TEAGR & + & - \\
CASHE & + & - \\
SISAL & + & - \\
SUGAR & + & - \\
OFRVE & + & - \\
OCROP & + & - \\
LIVES & + & - \\
FISHI & - & + \\
HUFOR & - & - \\
MININ & + & - \\
MEATD & + & - \\
GRAIN & + & - \\
PFOOD & + & + \\
BEVER & + & + \\
CLOTH & + & - \\
WOODP & + & - \\
CHEMI & + & - \\
RUPLA & + & - \\
GLASS & + & - \\
METAL & + & - \\
EQUIP & + & - \\
UTILI & + & - \\
CONST & + & + \\
TRADE & + & - \\
TRANS & + & - \\
ESTAT & + & - \\
ADMIN & + & - \\
PRIVS & - & - \\
\hline \hline & + & - \\
\hline
\end{tabular}

